\title{
Histone Deacetylase Inhibitors and Phenotypical Transformation of Cancer Cells
}

\author{
Anna Wawruszak 1,*(D), Joanna Kalafut ${ }^{1}$, Estera Okon ${ }^{1}$, Jakub Czapinski ${ }^{1,2}$, Marta Halasa ${ }^{1}$, \\ Alicja Przybyszewska ${ }^{1}$, Paulina Miziak ${ }^{1}$, Karolina Okla ${ }^{3,4}$, Adolfo Rivero-Muller ${ }^{1,5,+}$ (D) and \\ Andrzej Stepulak ${ }^{1,+}$ \\ 1 Department of Biochemistry and Molecular Biology, Medical University of Lublin, Chodzki 1 St., \\ 20-093 Lublin, Poland; joanna.kalafut@umlub.pl (J.K.); estera.okon@umlub.pl (E.O.); \\ jakub.czapinski@umlub.pl (J.C.); martaahalasa@gmail.com (M.H.); alicja.przybyszewska@umlub.pl (A.P.); \\ paulina.miziak@umlub.pl (P.M.); adolfo.rivero-muller@umlub.pl (A.R.-M.); \\ andrzej.stepulak@umlub.pl (A.S.) \\ 2 Postgraduate School of Molecular Medicine, Medical University of Warsaw, Trojdena 2a St., 02-091 Warsaw, \\ Poland \\ 3 The First Department of Gynecologic Oncology and Gynecology, Medical University of Lublin, \\ Staszica 16 St., 20-081 Lublin, Poland; karolina.okla@umlub.pl \\ 4 Tumor Immunology Laboratory, Medical University of Lublin, Staszica 16 St., 20-081 Lublin, Poland \\ 5 Faculty of Science and Engineering, Cell Biology, Abo Akademi University, Tykistokatu 6A, 20520 Turku, \\ Finland \\ * Correspondence: anna.wawruszak@umlub.pl; Tel.: +48-81-448-6350 \\ + These authors contributed equally to this work.
}

Received: 23 December 2018; Accepted: 22 January 2019; Published: 27 January 2019

\begin{abstract}
Histone deacetylase inhibitors (HDIs) are a group of potent epigenetic drugs which have been investigated for their therapeutic potential in various clinical disorders, including hematological malignancies and solid tumors. Currently, several HDIs are already in clinical use and many more are on clinical trials. HDIs have shown efficacy to inhibit initiation and progression of cancer cells. Nevertheless, both pro-invasive and anti-invasive activities of HDIs have been reported, questioning their impact in carcinogenesis. The aim of this review is to compile and discuss the most recent findings on the effect of HDIs on the epithelial-mesenchymal transition (EMT) process in human cancers. We have summarized the impact of HDIs on epithelial (E-cadherin, $\beta$-catenin) and mesenchymal (N-cadherin, vimentin) markers, EMT activators (TWIST, SNAIL, SLUG, SMAD, ZEB), as well as morphology, migration and invasion potential of cancer cells. We further discuss the use of HDIs as monotherapy or in combination with existing or novel anti-neoplastic drugs in relation to changes in EMT.
\end{abstract}

Keywords: cancer; HDI; HDAC; EMT; MET; cadherin; catenin; vimentin; migration; invasion

\section{Introduction}

Epithelial-mesenchymal transition (EMT) is a biological reversible process in which cells undergo multiple biochemical changes-lose their epithelial properties, including cell-cell adhesion and cell polarity, and acquire mesenchymal phenotype, including the ability to invade the extracellular matrix (ECM) and potentially migrate to the distant places. Induction of EMT includes reorganization of cytoskeleton proteins, activation of transcription factors and production of extracellular matrix-degrading enzymes [1,2]. Recent studies revealed the large role of epigenetic mechanisms including DNA methylation, chromatin rearrangement, histone modifications and non-coding RNAs in the initiation and progression of cancers [3]. Histone modifications play important 
roles in gene expression regulation via changes in chromatic structure and recruitment of epigenetic modulators, which also controls phenotypic transformation. Abnormal histone modification patterns are closely associated with numerous diseases including cancers, thus they are considered promising biomarkers [4].

Histone deacetylase inhibitors (HDIs) are effective anti-cancer agents which, in monotherapy and/or in combination with conventional chemotherapeutics, exhibit anti-neoplastic properties through cell-cycle arrest, inhibition of migration and invasion, induction of differentiation and apoptosis in many types of cancer cells [5-8]. Combinations of HDIs with e.g., thienotriazolodiazepine (JQ1), an inhibitor of bromodomain-containing acetylation reader proteins like bromodomain-containing protein 4 (BRD4), have shown efficacy in several cancer types, including urothelial carcinoma [9]. It has been reported that HDIs can reverse EMT, a process called mesenchymal-epithelial transition (MET), through, inter alia, unblocking of E-cadherin repression in solid cancers [10]. Thus, suggesting that HDIs have a therapeutic role in inhibition of EMT in cancer cells [11-14]. However, conflicting results have been also found, where HDIs induced EMT by reversing stem cell-like properties and enhanced metastasis [15]. In this review we discuss the impact of various HDIs on epithelial and mesenchymal markers, as well as on migration and invasion of cancer cells (Figure 1). The efficacy of HDIs has been demonstrated in both in vitro and animal models in monotherapy and/or in combination with existing or novel chemotherapeutics.

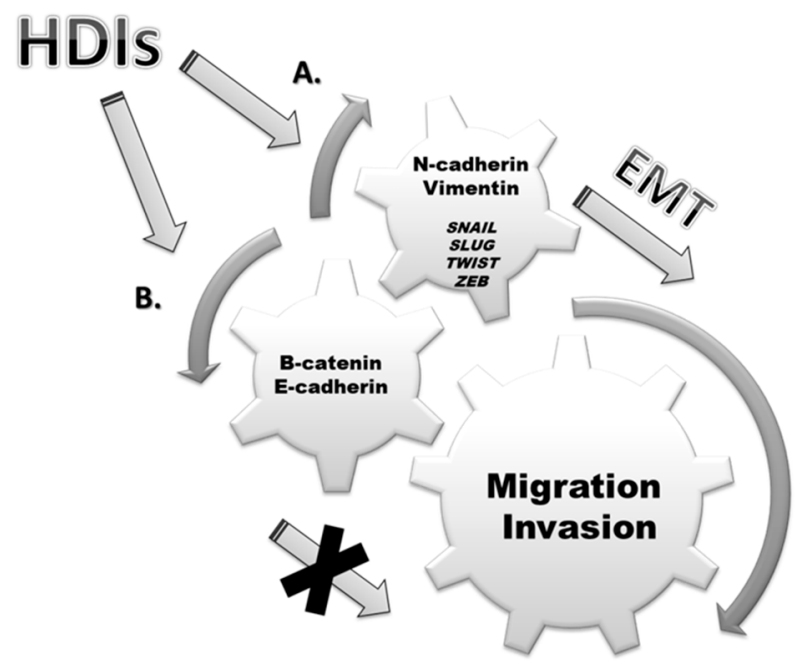

Figure 1. Histone deacetylase inhibitors (HDIs) modulate expression of epithelial-mesenchymal transition (EMT) markers as well as stimulate or inhibit migration and invasion of cancer cells. (A) HDIs induce EMT by increasing migration and invasion of cancer cells by upregulation of mesenchymal markers (N-cadherin, vimentin) and EMT-related transcription factors (SNAIL, SLUG, TWIST, ZEB). (B) HDIs upregulate expression of epithelial markers (E-cadherin, $\beta$-catenin) and consequently inhibit EMT, migration and invasion of cancer cells.

\section{Histone Deacetylases (HDACs) and Histone Deacetylase Inhibitors (HDIs)}

Epigenetic regulation of gene expression is largely modulated throughout chromatin and nucleosome remodeling, which involves histone post-translational modifications (PTMs) [16]. These PTMs result in dynamic shifts between transcriptionally active and suppressed states of chromatin [17]. Histone PTMs include methylation, phosphorylation, acetylation, sumoylation, ubiquitination and ADP-ribosylation [18]. Histone acetylation, one of the most extensively studied PTMs of histones, is regulated by the balance between histone deacetylases (HDACs) and histone acetyltransferases (HATs) (Figure 2A) [16]. HATs are enzymes that transfer an acetyl group from acetyl-CoA to $\varepsilon$-amino lysine residues located on $\mathrm{N}$-terminus of histones [19]. In contrast, HDACs are responsible for removing the acetyl group from the acetylated lysine residues. This reversible reaction is crucial for 
chromatin structure stabilization and transcriptional regulation of gene expression [20,21]. Histone hypoacetylation by HATs leads to an open chromatin conformation, which is easily available for transcription factors, through abolition of the positively charged residues of histones and negatively charged DNA. HDACs promote transcriptional silencing through deacetylation and thus chromatin compression (Figure 2B) [22].
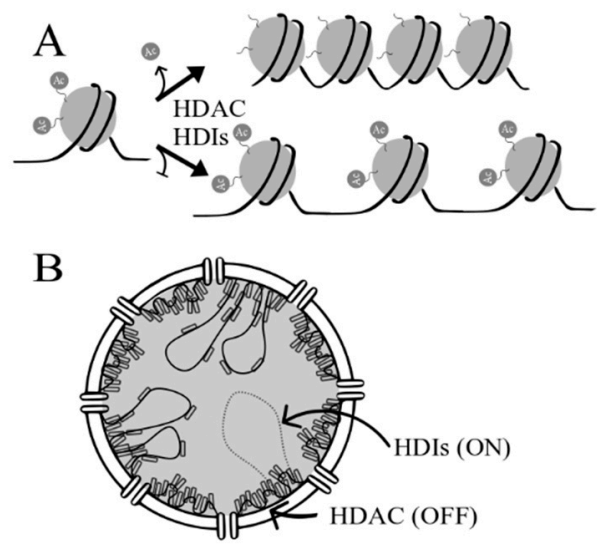

Figure 2. (A) Effect of histone deacetylase inhibitors (HDIs) on chromatin remodeling. Acetylation (Ac) of histones results in changes in chromatin conformation, where non-acetylated histones form heterochromatin (close chromatin) while acetylated histones result in relaxed chromatin—allowing DNA-binding by transcription factors. (B) Chromosomal landscape in the nucleus in the presence and absence of HDIs. Closed chromatin is near the nuclear envelope, while relaxed chromatin, where transcription is possible, is found in the middle of nucleus.

\subsection{HDACs}

The 18 HDACs in humans are classified into four classes according to their sequence homology with yeast proteins and cofactor dependency [23]. The class I shares common domains with yeast transcriptional regulator RPD3 and includes HDAC1, HDAC2, HDAC3 and HDAC8 and they are placed into the nuclear compartment. Class II of HDACs is shared into two subclasses (IIa and IIb) and is closely related with HDA1 in yeast [24]. The class IIa encompasses HDAC4, HDAC5, HDAC7, and HDAC9, whereas class IIlb includes HDAC6 and HDAC10 [25,26]. Class IIa HDACs are inactive on acetylated substrates, thus differing from class I and IIb enzymes. It has been demonstrated that class IIa HDACs are very inefficient enzymes on standard substrates $[27,28]$. Class II HDACs (HDAC4, HDAC5, HDAC7 and HDAC9), compared to HDAC class I, possess limited enzymatic activity on their own. Instead, they appear to act as gene-specific transcriptional corepressors mainly as components of multiprotein complexes [29-31]. The class II HDACs migrate between cytoplasm and nucleus. The class III (sirtuins) includes seven members (SIRT1-SIRT7) and they share common domains with yeast silent information regulator 2 (SIR2) [27]. Class IV contains only one member - HDAC11 [32]. Catalytical activity of class I, II, IV is strongly associated with presence of zinc ion in their active site. In contrast, class III requires nicotinamide adenine dinucleotide (NAD) as a cofactor during their catalytical reaction $[25,26]$.

Imbalances between the activities of HDACs and HATs are associated with a plethora of diseases [33-36]. The epigenetic aberrations of gene expression caused by increased activity of HDACs play a pivotal role in cancer development and progression [37]. Given the fact that the activity of HDACs is dysregulated in many types of cancers [38-40], HDACs have been considered as therapeutic targets for the treatment of neoplasms, indeed HDIs have become promising anti-cancer agents [41,42].

According to the Human Protein Atlas class I HDACs are expressed in variety types of tumors (Figure 3) [43-46]. The data is presented by the percentage (\%) of analyzed tumors with HDACs expression at high or medium level. HDAC2 was found expressed in $100 \%$ of multiple tumors. In the case of renal cancer HDAC2 is expressed $100 \%$ of cases, while other members do not exceed 
$50 \%$ (Figure 3) [44]. HDAC1 expression is comparatively high with exception of renal cancer and glioma [43]. The amount of patients with HDAC3 expression in ovarian cancer is significantly lower (20\%) comparing to the other members of class I-all others with almost $100 \%$ incidence [45]. The last member of class I, HDAC8 is absent in colorectal, testis and breast cancer. Additionally, the score for patients with HDAC8 expression in liver cancer is notably lower (9\%) compared to other members-HDAC1: 90\%, HDAC2: 75\% and HDAC3: 50\% (Figure 3) [43-46].

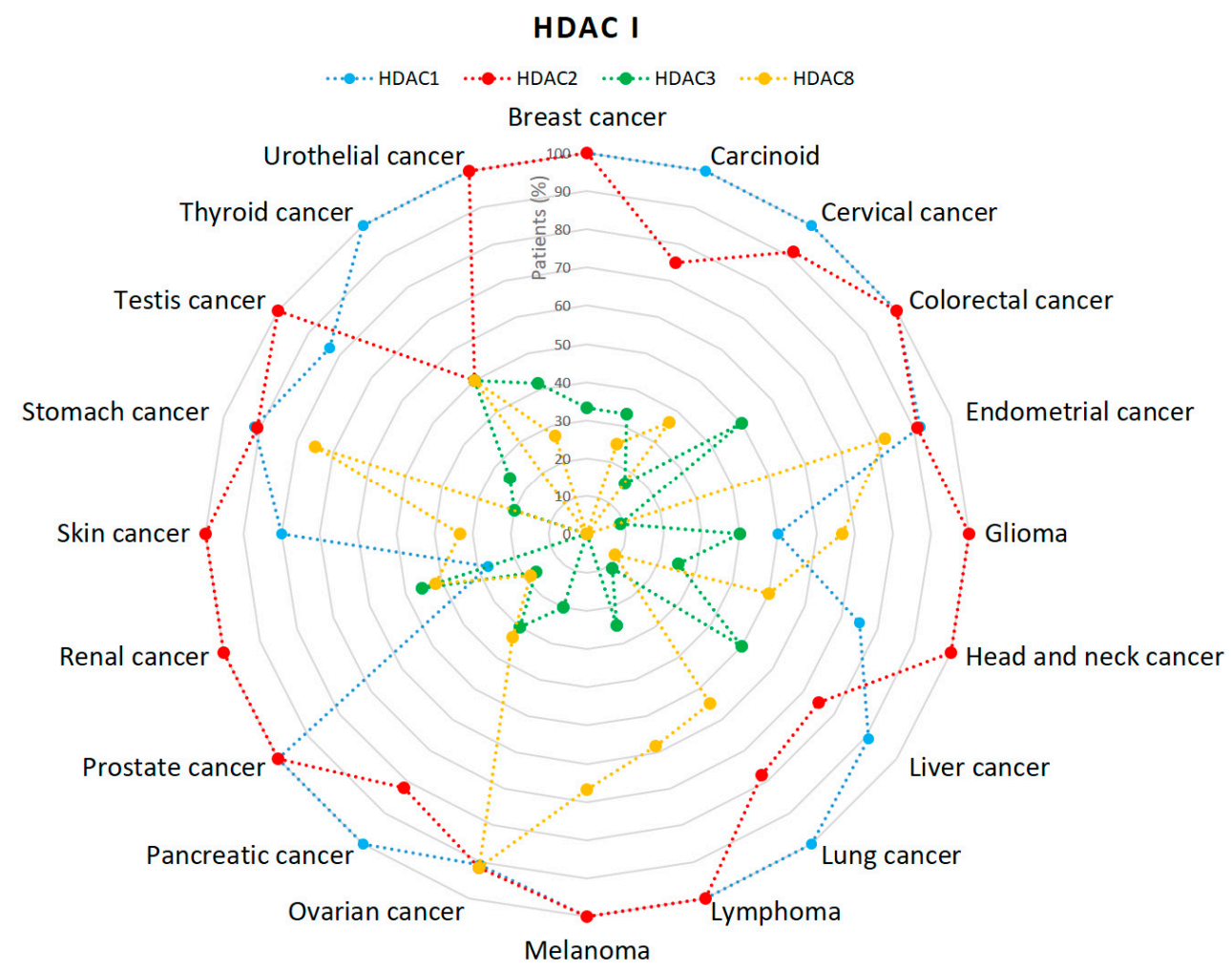

Figure 3. Percentage (\%) of patients with high or medium HDACs class I expression levels in different types of cancer [43-46].

Class II HDACs are more varied than class I in terms of incidence in different cancers. High incidence of class IIa HDACs (HDAC4, HDAC5 and HDAC9) [47-49], is associated with colorectal and breast cancers. Interestingly, very low level of patients with HDAC5 (9\%) and HDAC9 (8\%) expression is observed in renal cancer (Figure 4) $[48,49]$. The last member of IIa class-HDAC7 is associated mainly with lung cancer. Inhibition of HDAC7 results in restraining of lung cancer development [50]. HDAC10 (IIb class) is expressed in virtually all patients' tumors $(100 \%)$ in every single analyzed type of cancer [51]. In contrast, the number of tumors with HDAC6 expression is very diverse in different types of cancer [52].

SIRT3, SIRT5, SIRT6 and SIRT7 are expressed in large part of tumors [53-56]. Of note is SIRT2, which is only expressed with gliomas among all analyzed types of cancer (Figure 5) [57].

There is no available data in Human Protein Atlas regarding the expression of HDAC11 in different tumors. Yet, depletion of HDAC11 has an impact on cancer cells, including breast, ovarian, colon and prostate cells. HDAC11 is associated with apoptosis induction and inhibition of cell metabolic activity. Conversely, depletion of HDAC11 does not affect colon HCT-116 and prostate PC-3 cells [58]. 


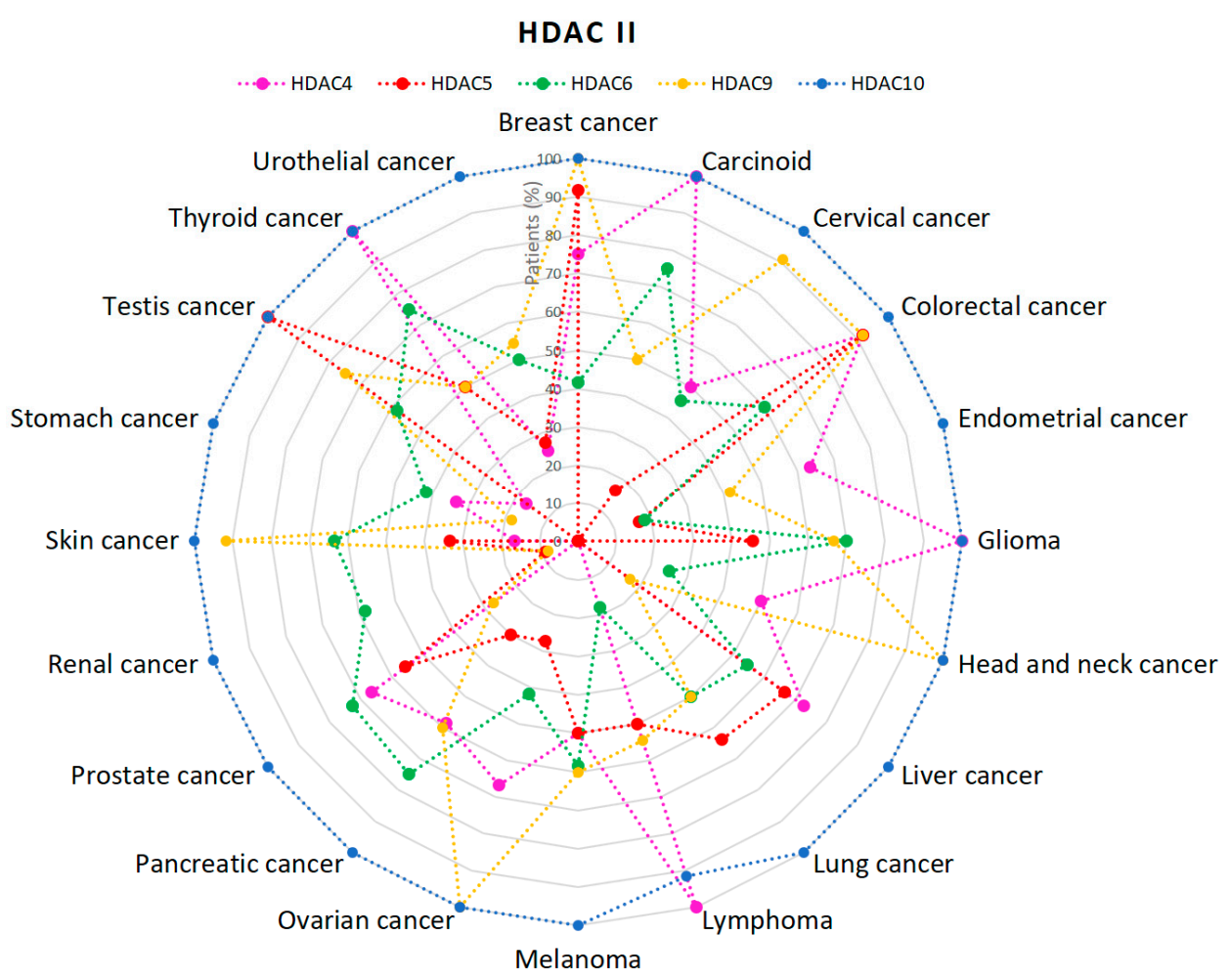

Figure 4. Percentage (\%) of patients with high or medium HDACs class II expression levels in different types of cancer. HDAC7 was not analyzed [47-52].

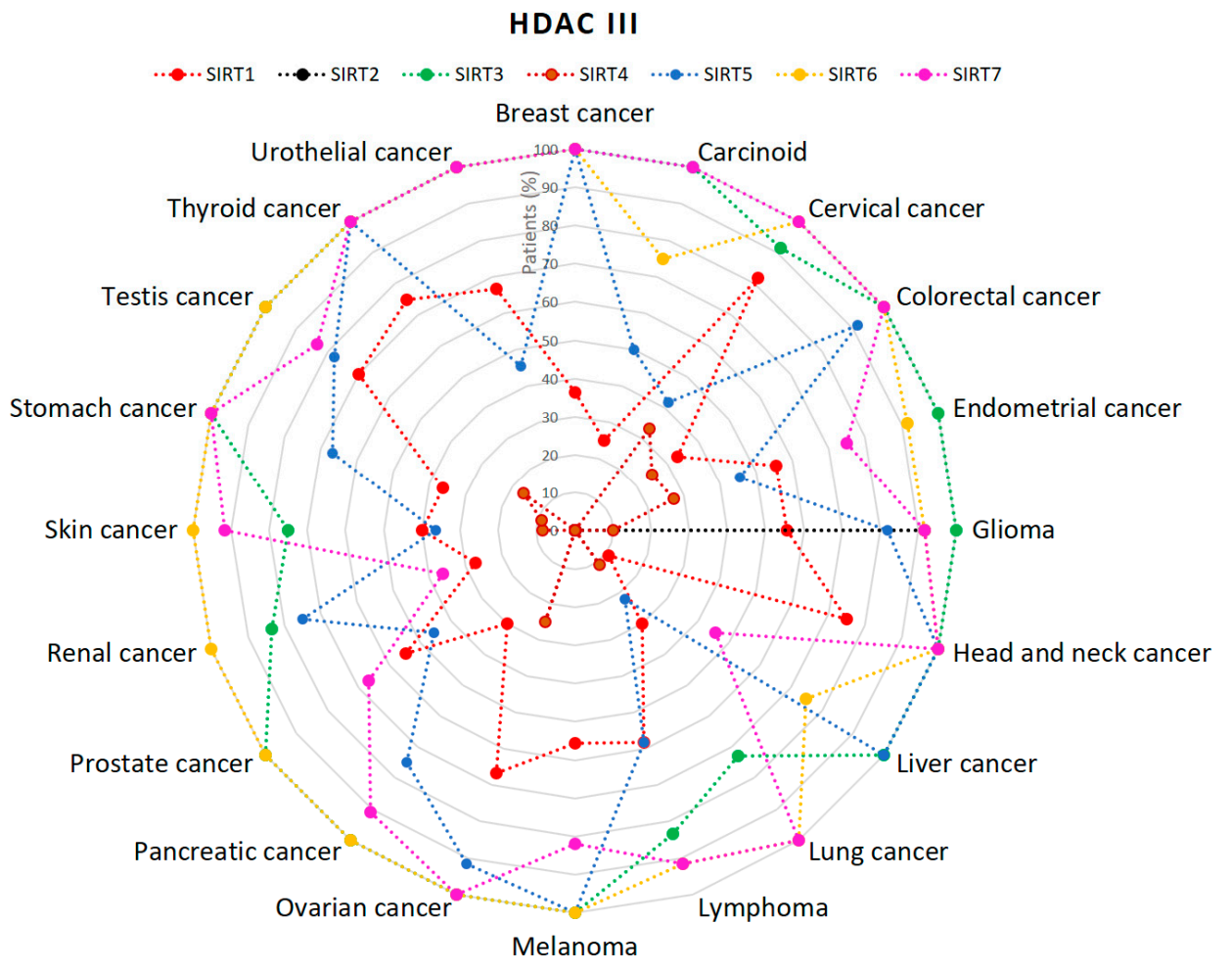

Figure 5. Percentage (\%) of patients with high or medium HDACs class III expression levels in different types of cancer. There is no available data regarding the expression of HDAC11 (HDAC IV) [53-60].

According to the Human Protein Atlas high or medium expression of HDAC1, HDAC2, HDAC9, HDAC10, SIRT3, SIRT5, SIRT6, SIRT7 is present in $100 \%$ of patients with breast cancer (Figure 6A); 
while in carcinoid tumors is HDAC1, HDAC4, HDAC9, SIRT7 (Figure 6B). In cervical cancer HDAC1, HDAC10, SIRT6, SIRT7 are always present (Figure 6C); whist in colorectal cancer is HDAC10, SIRT6, SIRT7 (Figure 6D). Endometrial cancer only expresses in 100\% of cases HDAC10 and SIRT3 (Figure 6E). $100 \%$ penetrance of HDAC2, HDAC4, HDAC10 and SIRT3 in glioma (Figure 7A); HDAC2, HDAC9, HDAC10, SIRT3, SIRT5, SIRT6, SIRT7 in head and neck cancer (Figure 7B); HDAC10, SIRT3, SIRT5 in liver cancer (Figure 7C); HDAC1, HDAC10, SIRT6, SIRT7 in lung cancers (Figure 7D); HDAC1, HDAC2, HDAC4 in lymphoma (Figure 7E); HDAC1, HDAC2, HDAC10, SIRT3, SIRT5, SIRT6 in melanoma (Figure 8A); HDAC9, HDAC10, SIRT3, SIRT6, SIRT7 in ovarian cancer (Figure 8B); while HDAC1, HDAC10, SIRT3, SIRT6 in pancreatic cancer (Figure 8C).
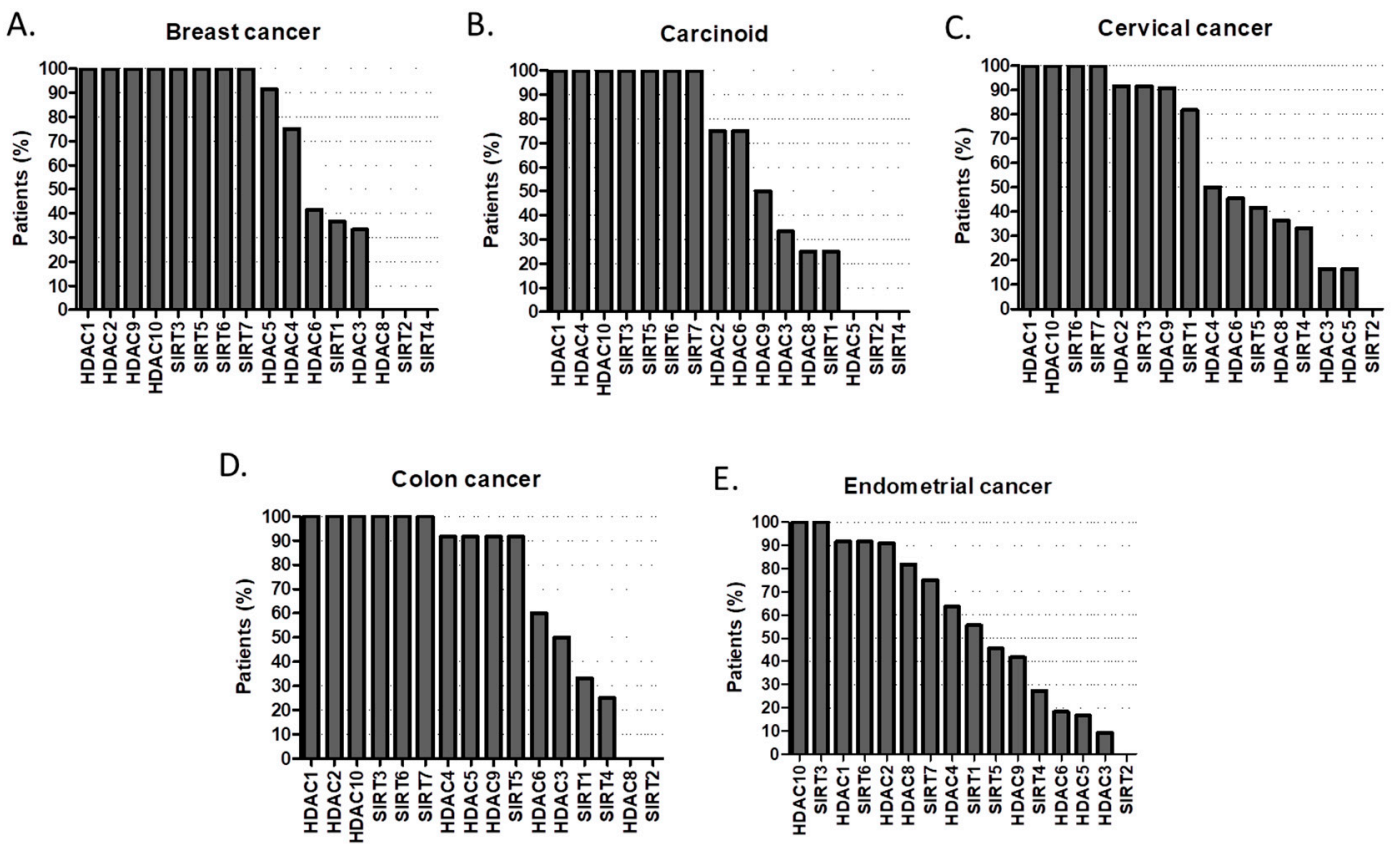

Figure 6. Percentage (\%) of tumors with high or medium HDAC protein expression levels in (A) breast cancer, (B) carcinoid, (C) cervical cancer, (D) colon cancer, (E) endometrial cancer [43-60].
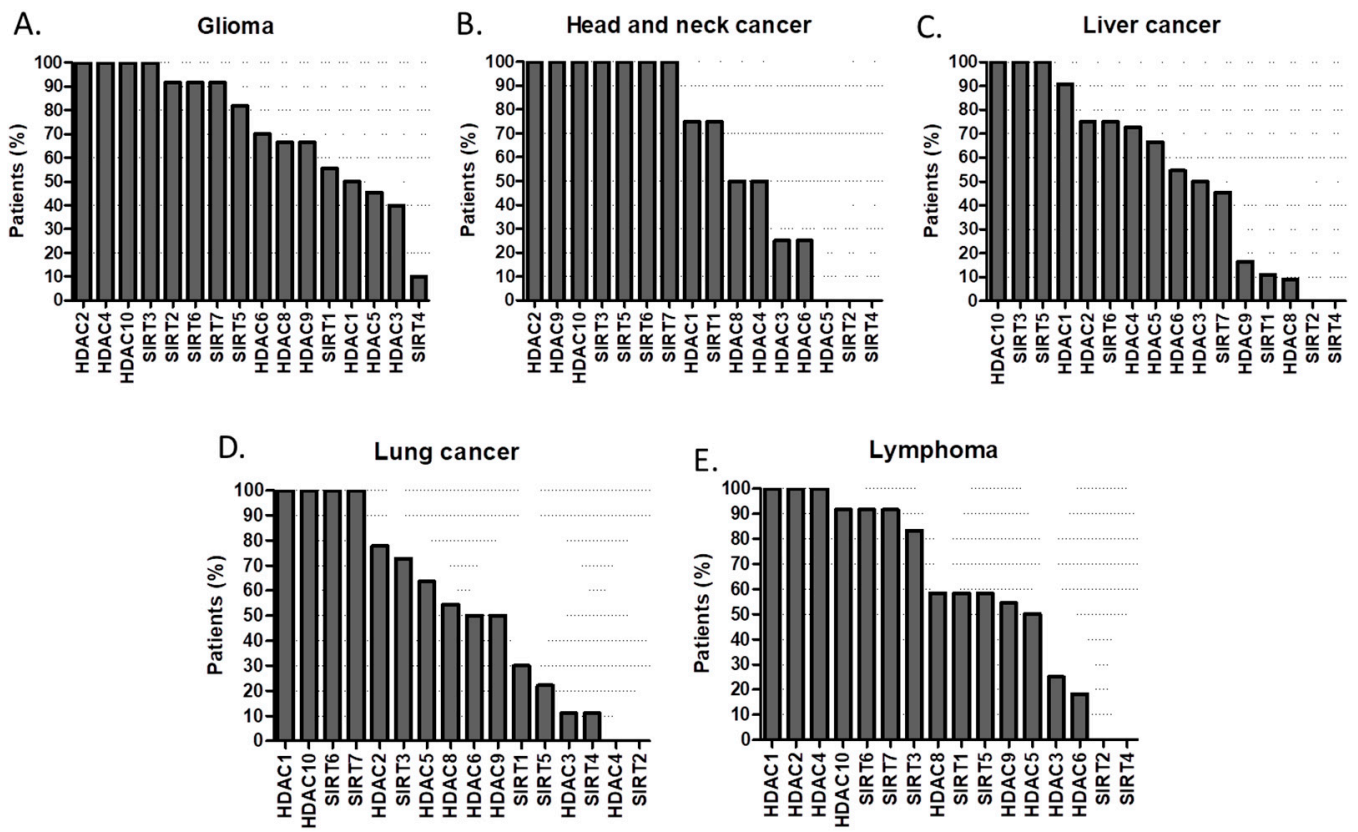

Figure 7. Percentage (\%) of tumors with high or medium HDAC protein expression levels in (A) glioma, (B) head and neck cancer, (C) liver cancer, (D) lung cancer, (E) lymphoma [43-60]. 

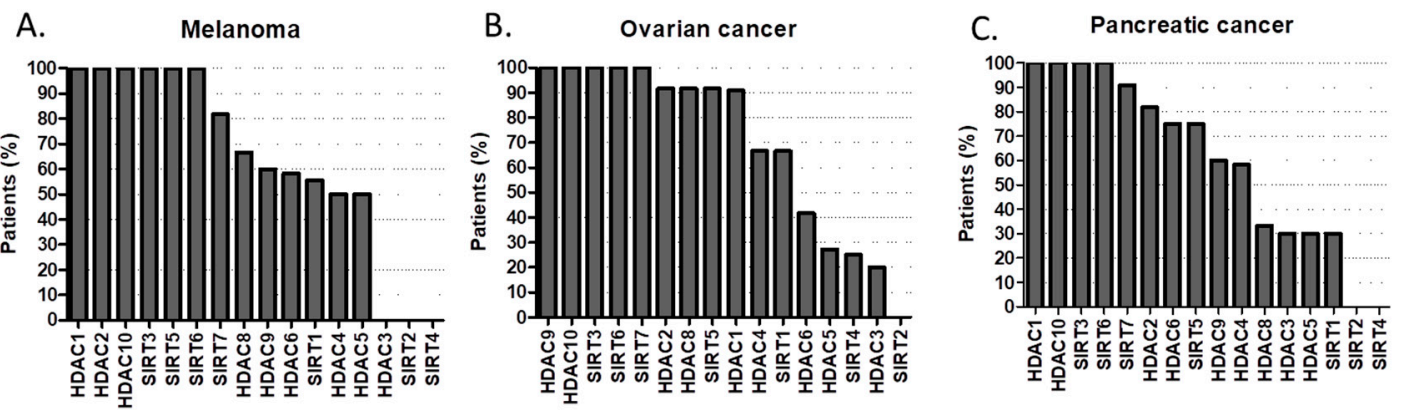

D.
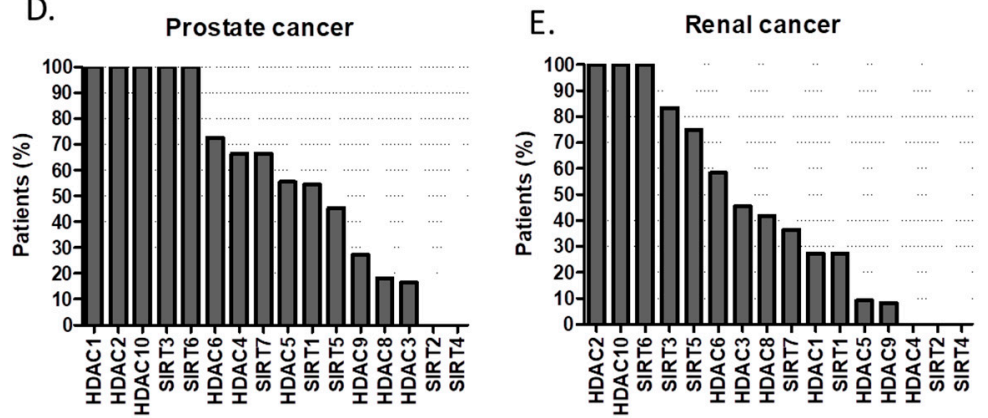

Figure 8. Percentage (\%) of tumors with high or medium HDAC protein expression levels in (A) melanoma, (B) ovarian cancer, $(\mathbf{C})$ pancreatic cancer, $(\mathbf{D})$ prostate cancer, $(\mathbf{E})$ renal cancer [43-60].

The same goes for HDAC1, HDAC2, HDAC10, SIRT3, SIRT6 in prostate cancer (Figure 8D); HDAC2, HDAC10 and SIRT6 in renal (Figure 8E) and skin cancers (Figure 9A); HDAC10, SIRT3, SIRT6, SIRT7 in stomach cancer (Figure 9B); HDAC2, HDAC5, HDAC10, SIRT3, SIRT6 in testicular cancer (Figure 9C); HDAC1, HDAC4, HDAC10, SIRT 3, SIRT5, SIRT6, SIRT7 in thyroid cancer (Figure 9D) and HDAC1, HDAC2, HDAC10, SIRT3, SIRT6, SIRT7 in urothelial cancer (UC) (Figure 9E) [43-60]. In urothelial cancer, not only up-regulation of HDAC2 and HDAC8, but also down-regulation of HDAC4, HDAC5 and HDAC7 mRNA are common findings. Selective targeting of HDAC2, HDAC8 and other HDACs dysregulated in UC result in a more consistent treatment response requires further research [61]. However, neither specific pharmacological inhibitors nor siRNA-mediated knockdown of HDAC8 reduced the viability of urothelial cancer cells (UCC), suggesting HDAC8 in not a good target for UC therapy $[62,63]$.

Histone targets for HDACs are: H3K9Ac (acetylation in lysine 9 of histone 3), H3K18Ac, H4K5Ac, H4K8Ac, H4K12Ac and H4K16Ac in lung cancer, H3Ac, H4Ac and H3K18Ac in prostate cancer, H3K18Ac, H4K12Ac and H4K16Ac in breast cancer [64].

HDACs also deacetylate non-histone proteins $[65,66]$. Acetylation of non-histone proteins is a part of key cellular process in physiology and diseases, and links with signal transduction, gene transcription, metabolism, DNA damage repair, cell division, autophagy and protein folding. Acetylation affects the function of proteins through various mechanisms, including regulation of protein stability, enzymatic activity and crosstalk with other post-translational modifications [66]. One of the non-histone target of HAT acetylation is the tumor suppressor p53. Acetylation of p53 by p300/CBP (CREB-binding protein) activates its sequence-specific DNA binding activity and increases activation of its target genes. Deacetylation of p53 by SIRT1 decreases the ability of p53 to activate the cell cycle inhibitor p21, which takes part in DNA repair [66,67]. YY1 is sequence-specific DNA-binding transcription factor involved in repressing and activating a diverse number of promoters. YY1 interacts with HATs (CBP and p300) and with most HDACs class I (HDAC1, 2 and 3) $[67,68]$. Moreover, acetylation regulates the DNA binding activity of high mobility group (HMG) proteins. In metastatic human colon adenocarcinoma cells HMGA-1 proteins are more highly acetylated in comparison to the non-metastatic precursors $[69,70]$. 

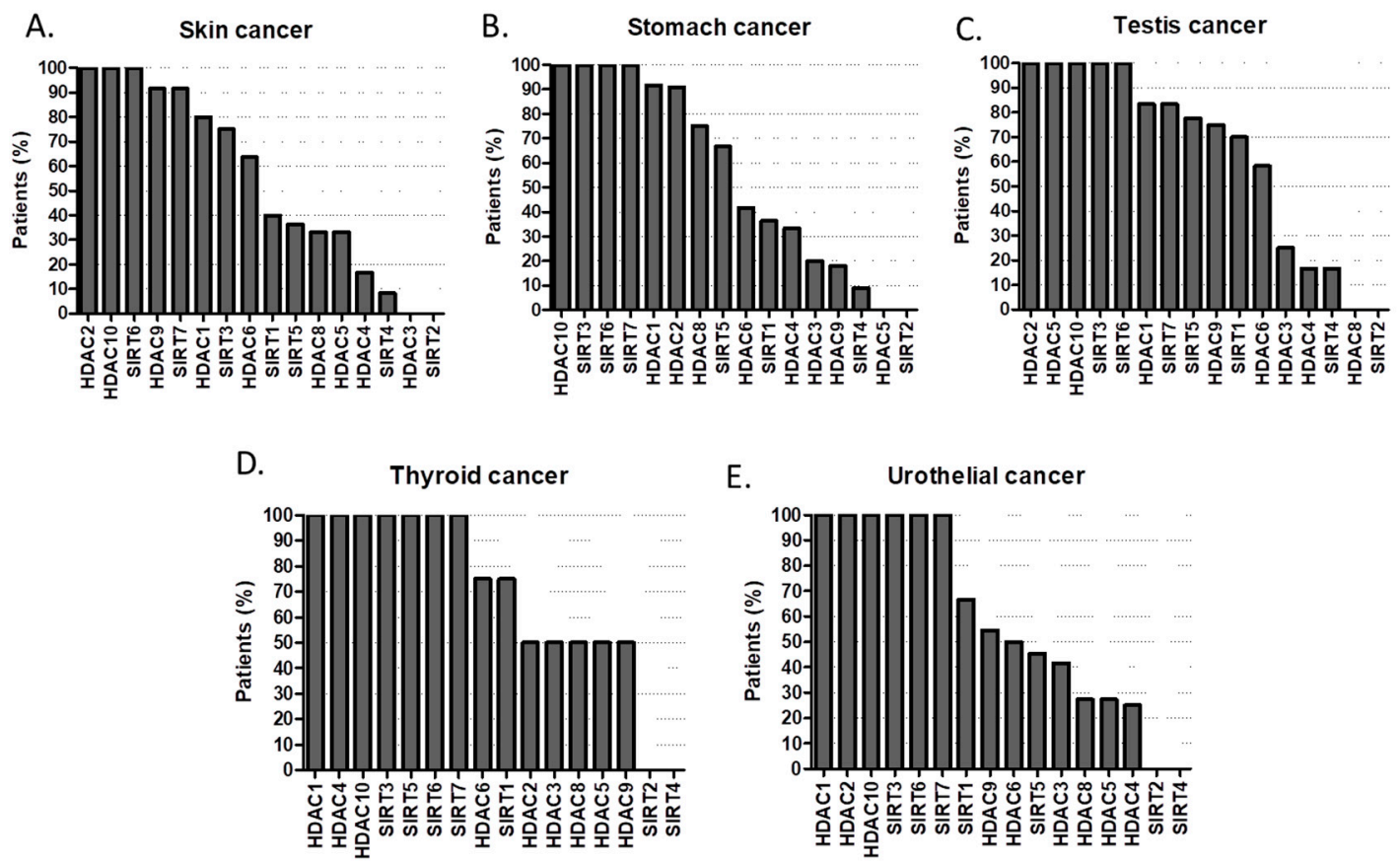

Figure 9. Percentage (\%) of tumors with high or medium HDAC protein expression levels in (A) skin cancer, (B) stomach cancer, (C) testis cancer, (D) thyroid cancer, (E) urothelial cancer [43-60].

Nuclear receptors (NRs) are the other class of transcription factors modulated by acetylation and deacetylation. CBP/p300 and TIP60 acetylate the androgen receptor (AR). Hormone-dependent activation of AR requires acetylation of lysines 630, 632 and 633. Deacetylation of AR by HDAC1 represses the function of AR [71]. The estrogen receptor (ER) is also acetylated by p300 but at lysines 299, 302 and 303 [67]. Another non-histone protein GATA-1 is acetylated by p300. GATA-1 is an important transcription factor in hematopoiesis and terminal differentiation of erythrocytes and megakaryocytes [72]. Erythroid Krüppel-like factor (EKLF) is a red cell-specific transcriptional activator. EKLF is acetylated and interacts with p300, CBP and P/CAF [73]. p300/CBP acetylates EKLF at lysine residues 288 and 302 located in the transactivation domain and zinc finger domain, respectively [67]. The myogenic protein (MyoD) requires CBP/p300 and PCAF acetylation to transactivate muscle-specific promoters [67]. The proliferation promoting members of the E2F family (E2F1, 2 and 3) also are acetylated by p300, CBP and PCAF, the latter acetylates E2F1 with the highest efficiency $[67,73]$. Acetylation and deacetylation also dynamically regulate the activity of NF- $\kappa \beta$ (nuclear factor kappa-light-chain-enhancer of activated $\beta$ cells). NF- $\kappa \beta$ is a protein complex that controls cell survival, transcription of DNA and cytokine production. The nuclear function of the NF- $k \beta$ transcription factor is regulated through acetylation of its RelA subunit by $\mathrm{p} 300 / \mathrm{CBP}$ at the lysines 218, 221, 310. Acetylation of lysine 221 in RelA subunit enhances DNA binding and impairs assembly with Iк $\beta \alpha$. While, acetylation at lysine 310 is needed for full transcriptional activity of RelA in the absence of effects on DNA binding and Ik $\beta \alpha$ assembly. Site-specific acetylation of RelA diversely regulates activities of NF- $\kappa \beta$ the transcription factor complex [74].

Acetylation regulates also activity of the molecular chaperone Hsp90. Hsp90 has important role in maturation of many proteins, including the ligand-inducible transcription factor glucocorticoid receptor (GR). Specifically HDAC6 seems to be a regulator of Hsp90 acetylation [67,75]. Moreover, hypoxia-inducible factor 1 (HIF-1) can be acetylated by ARD1 protein acetyltransferase. HIF-1 plays a main role in cellular adaptation to changes in oxygen availability. ARD1-mediated acetylation strengthen interaction of HIF- $1 \alpha$ with pVHL (the von Hippel-Lindau protein) and HIF- $1 \alpha$ ubiquitination, suggesting that the acetylation of HIF- $1 \alpha$ by ARD1 is critical to proteasomal degradation [76]. Transforming growth factor beta (TGF $\beta$ ) regulates multiple cellular processes via activation of Smad signaling pathways. p300 acetylates Smad7 on two lysine residues. These lysine 
residues are critical for Smurf-mediated ubiquitination of Smad7. Moreover, acetylation protects Smad7 from TGF $\beta$-induced degradation [77]. It has been also demonstrated that p300/CBP acetylates mastermind-like transcriptional coactivator-1 (Maml1), a Notch transcriptional co-factor, and thus regulates the strength of Notch-downstream signaling [78]. On the other hand, Notch signaling induces SIRT2 expression, which deacetylates and activates ALDH1A1 (aldehyde dehydrogenease), a marker commonly used to determine stem cells, particularly in breast cancer [79].

\subsection{HDIs}

HDIs are divided into four basic structural classes: short chain fatty acids (e.g., valproic acid (VPA), sodium butyrate (NaB), phenylbutyrate (PBA)), hydroxamic acids (e.g., vorinostat (SAHA), trichostatin A (TSA), panobinostat (LBH-589), belinostat (PXD-101), resminostat (4SC-201)), cyclic peptides (e.g., romidepsin (FK228), apicidin (CAS183506-66-3)), benzamides (e.g., entinostat (MS-275), mocetinostat (MGCD103), domatinostat (4SC-202)) [80,81]. HDIs differ significantly in their specificity for HDACs (Table 1). Most HDIs belonging to benzamide analogs (MS-275, MGCD0103, 4SC-202) and cyclic peptides (FK228, CAS183506-66-3) groups inhibit HDAC class I members only, while the majority of HDIs which are short-chain fatty acid can inhibit HDAC classes I and II [82,83]. Some of hydroxamic acid-derived compounds (SAHA, 4SC-201, PXD-101) are HDAC pan-inhibitors (Table 1). Pan-inhibitors characterize the lowest specificity, therefore they can inhibit various HDACs belonging to different classes [82,83].

Table 1. Histone targets of histone deacetylase inhibitors (HDIs).

\begin{tabular}{cccc}
\hline Class of HDI & HDI & HDAC Targets & Ref. \\
\hline \multirow{4}{*}{ Short chain fatty acid } & Phenylbutyrate (PBA) & Pan-inhibitor & {$[84]$} \\
& Sodium butyrate (NaB) & I, IIa & {$[85]$} \\
& Butyrate & I, IIa & {$[83]$} \\
& Valproic acid & I, IIa & {$[86]$} \\
\hline \multirow{2}{*}{ Hydroxamic } & Vorinostat (SAHA) & Pan-inhibitor & {$[87]$} \\
acid-derived & Belinostat (PXD-101) & Pan-inhibitor & {$[88]$} \\
compounds & Resminostat (4SC-201) & Pan-inhibitor & {$[83]$} \\
& Panobinostat (LBH589) & I, II & {$[83]$} \\
& Trochostatin A (TSA) & I, II & {$[24]$} \\
\hline \multirow{3}{*}{ Benzamides } & Entinostat (MS-275) & I & {$[89]$} \\
& Mocetinostat (MGCD103) & I & {$[90]$} \\
& Domatinostat (4SC-202) & I & {$[80]$} \\
\hline \multirow{2}{*}{ Cyclic peptides } & Romidepsin (FK228) & I & {$[91]$} \\
& Apicidin (CAS183506-66-3) & I & {$[83]$} \\
\hline
\end{tabular}

In the past decade, many HDIs have been found to possess powerful anti-cancer activity, including induction of apoptosis [92,93], growth arrest and differentiation [94], suppression of EMT, cell migration and invasion [13], as well as inhibition of angiogenesis [95], both in vitro and in vivo [42]. Additionally, HDI-induced suppression of tumor growth and apoptosis of neoplastic cells take place without noticeable effects in normal cells [5]. Currently, four HDIs-vorinostat, romidepsin (antibiotic) [96], belinostat and panobinostat-have been approved by the Food and Drug Administration (FDA) for the treatment of cutaneous and peripheral T-cell lymphoma and multiple myeloma [18]. Several HDIs are in various phases of clinical trials, either as monotherapy and in combination with existing or novel anti-cancer drugs [18]. The molecular mechanisms for the anti-cancer activity of HDIs have not been fully resolved, partly as their effects are cell type-, dose- and time-dependent. It is worth mentioning that HDIs do not only affect histone-DNA complexes, but also the acetylation status of non-histone proteins (e.g., STAT3, p53 transcription factors) $[17,18,97]$. 


\section{Epithelial-Mesenchymal Transition (EMT)}

EMT is an essential physiological process during embryogenesis, histogenesis, organogenesis and wound healing. Yet, it can be also exploited during pathological processes such as fibrosis or tumor progression $[98,99]$. EMT is a reversible cellular process where epithelial cells acquire a mesenchymal-phenotype. Epithelial cells are connected by intercellular junctions such as: desmosomes, tight junctions (TJ) and adherent junctions (AJ), in contrast to mesenchymal cells, which do not cling to each other [100,101]. The consequence of EMT is disappearance of adhesion between epithelial cells through loss of junctions structures and apical-basal polarization. The new-formed mesenchymal cells acquire high migratory capabilities and invasive properties [102]. EMT is strongly associated with cancer metastasis as well as with presence of the circulating tumor cells (CTC). Moreover, EMT induces chemo- and radio-therapy resistance in many kinds of tumors [102,103]. Throughout EMT, the cancer cells endure frequently molecular events, for instance, a decrease of the level of epithelial markers (E-cadherin, cytokeratins) and an increase of the level of mesenchymal markers (N-cadherin, vimentin) (Figure 3). Expression of EMT markers in primary tumors has been linked with cancer progression and poor medical prognosis [104,105].

EMT is induced by growth factors including: transforming growth factor, hepatocyte growth factor, epithelial growth factor, fibroblast growth factor and insulin growth factor. All of them indirectly modify EMT transcription factors [106] (EMT-TFs), including: SNAIL and ZEB1/ZEB2 families, as well as TWIST1/TWIST2. Vertebrates have 3 SNAIL family members: SNAIL1, SNAIL2 and SNAIL3. These TFs have a highly conserved C-terminal organization, able to recognize and bind to the E-cadherin promoter. Moreover, the $N$-terminal domain of SNAIL (SNAG) interacts with transcriptional co-repressors, including Sin $3 \mathrm{~A} / \mathrm{HDAC} 1 / 2$ complex and polycomb complex 2 . Hence, the activation of SNAIL/SLUG promotes E-cadherin gene (CDH1) downregulation and contributes to an increase of cell migration and invasion [106,107]. The ZEB family of TFs downregulates CDH1 expression and upregulates mesenchymal markers such as $\mathrm{N}$-cadherin gene $(\mathrm{CDH} 2)$, vimentin and fibronectin. ZEB members are also responsible for increase of cell migration and invasion [108]. TWIST1 is able to simultaneously upregulate $C D H 1$ and downregulate $C D H 2$ expression. Post-transcriptional gene expression is regulated by small non-coding RNAs, such as: miRNA-200 and miRNA-34. Where epithelial cells express miRNA-200 and miRNA-34 whilst mesenchymal cells do not [109].

The balance between EMT and MET processes regulates cell plasticity [110]. However, nowadays an intermediate stage between fully-epithelial and fully-mesenchymal states has been recognized-hybrid E/M state. The identification of EMT/MET or hybrid E/M states is difficult to observe because these processes run smoothly and interchangeably [110] (Figure 10). Cancer cells with hybrid E/M phenotype have cell-cell adhesion properties as well as migration abilities, simultaneously [109]. Recent data suggest that cells with E/M hybrid phenotypes show stronger metastatic properties as well as survival in circulation [111,112]. Hybrid E/M cells are similar or more resistant to drug-treatments in comparison to fully EMT cells [111]. 


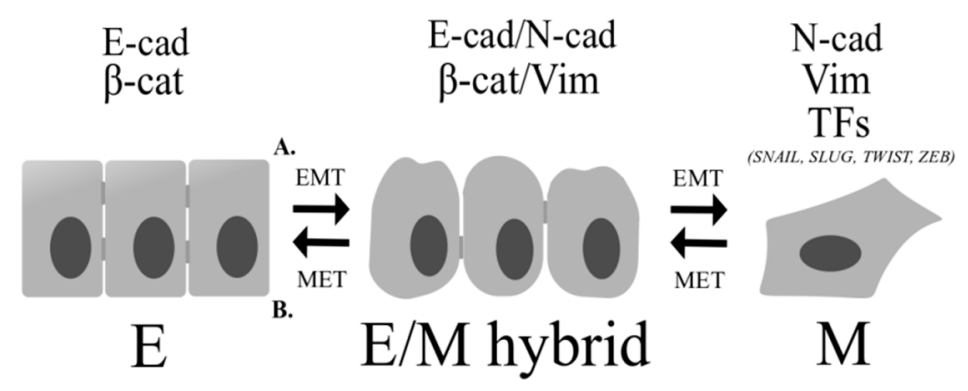

Figure 10. Phenotypical transformation of cells during the epithelial-mesenchymal transition (EMT) and mesenchymal-epithelial transition (MET) processes. (A) During EMT epithelial cells lose their polarized organization and acquire migratory and invasive capabilities by increase in mesenchymal markers (N-cadherin, vimentin) and EMT-related transcription factors (TFs) (SNAIL, SLUG, TWIST, ZEB). (B) During MET cells re-acquire epithelial properties. Epithelial cells are connected by intercellular junctions and they exhibit apical-basal polarization. The intermediate stage between fully-epithelial and fully-mesenchymal states has been described as E/M hybrid state. Cancer cells with E/M hybrid phenotype have cell-cell adhesion properties as well as migration abilities, simultaneously. E: epithelial; E/M hybrid: epithelial/mesenchymal hybrid; M: mesenchymal; E-cad: E-cadherin; $\beta$-cat: $\beta$-catenin; N-cad: N-cadherin; Vim: vimentin; TFs: transcription factors; SNAIL, SLUG, TWIST, ZEB: mesenchymal transcription factors.

\section{EMT and Cancers}

EMT is the result of a series of epigenetic changes including chromatin remodeling and histone modifications. Acetylation and metylation of histones play an important role in tumor progression [41]. For this very reason, HDIs are considered as modifiers of EMT-related factors expression, although this effect is cancer-type dependent [113]. Hereby we will analyse the available data on HDIs in different tumor types.

\subsection{Lung Cancer}

HDIs have been investigated for their roles as inhibitors of migratory potential. Indeed, TSA inhibits migration of irradiated human epithelial A549 lung cancer cells through decreasing of SNAIL and ZEB expression. The expression of E-cadherin and N-cadherin in irradiated-cells treated with TSA are inverted as compared to radiation-only pretreatment. Radiation-TSA treatment also resulted in upregulation of ZO-1 and $\beta$-catenin (epithelial markers), compared with alone-radiation pretreatment [114]. Moreover, it has been shown that the inhibitory effect for TGF- $\beta 1$-induced EMT in irradiated A549 cells pretreated with TSA is connected with inhibiting of SNAIL and SLUG activity [115]. TSA supported with silibinin, a natural flavanone compound from silymarin, significantly increases E-cadherin level by downregulation of ZEB1, while silibinin alone is not able to silence E-cadherin expression in non-small cell lung cancer (NSCLC H1299 cells). Interestingly, the level of E-cadherin after $48 \mathrm{~h}$ of TSA+silibinin treatment was significantly restored, compared with the level of E-cadherin after $48 \mathrm{~h}$ of TSA-alone [116]. VPA was able to partially inhibit EMT in A549 cells, through decreasing histone deacetylation level. Additionally, the cellular spindle-shape effect, which is characteristic for mesenchymal cells, induced by TGF- $\beta$ is reduced after VPA treatment. Although there is no direct interaction between VPA and TGF- $\beta 1$ [117].

At odds with other HDIs, SAHA-treated A549 cells responded by decreasing of E-cadherin expression and increasing of vimentin expression, with the acquisition of a mesenchymal phenotype. The E-cadherin downregulation is inversely correlated to SLUG expression [118]. Nevertheless, SAHA, as well as panobinostat, induce upregulation of GAS5-AS1 expression in a dose-dependent manner in NSCLC cells, which is connected with inhibiting migration of NSCLC cells [119] (Table 2). 
Table 2. Influence of histone deacetylase inhibitors (HDIs) on epithelial-mesenchymal transition (EMT) markers, transcription factors, morphology, migration and invasion of cancer cells in vitro and in vivo.

\begin{tabular}{|c|c|c|c|c|c|c|c|c|c|c|c|}
\hline Type of Cancer & $\begin{array}{c}\text { HDI } \\
\text { (Individually or } \\
\text { in Combination) }\end{array}$ & $\begin{array}{l}\text { Experimental } \\
\text { Model }\end{array}$ & Type of Treatment & E-cadherin & B-catenin & $\mathrm{N}$-cadherin & Vimentin & $\begin{array}{l}\text { Transcription } \\
\text { Factors }\end{array}$ & $\begin{array}{l}\text { Changes in } \\
\text { Morphology }\end{array}$ & $\begin{array}{l}\text { Migration and } \\
\text { Invasion }\end{array}$ & Ref. \\
\hline Lung cancer & SAHA & $\begin{array}{l}\text { A549 cells } \\
\text { in vitro }\end{array}$ & $\begin{array}{l}\text { cells treated with SAHA vs. } \\
\text { untreated cells }\end{array}$ & $\downarrow$ & $\rightarrow$ & N/A & $\uparrow$ & $\uparrow S L U G$ & $\begin{array}{c}\text { from cobblestone to } \\
\text { mesenchymal } \\
\text { spindle-like }\end{array}$ & $\uparrow$ migration & [118] \\
\hline Lung cancer & TSA & $\begin{array}{l}\text { A549 cells } \\
\text { in vitro }\end{array}$ & $\begin{array}{l}\text { irradiated cells treated with TSA vs. } \\
\text { irradiated cells }\end{array}$ & $\uparrow$ & $\uparrow$ & $\downarrow$ & $\downarrow$ & $\downarrow S N A I L, Z E B$ & $\begin{array}{l}\text { reduction of } \\
\text { mesenchymal-like } \\
\text { phenotype }\end{array}$ & $\downarrow$ migration & $\begin{array}{l}{[114]} \\
{[115]}\end{array}$ \\
\hline Lung cancer & TSA + silibinin & $\begin{array}{l}\text { H1299 cells } \\
\text { in vitro }\end{array}$ & $\begin{array}{l}\text { cells treated with TSA and silibinin } \\
\text { vs. cells treated with silibinin }\end{array}$ & $\uparrow$ & N/A & N/A & N/A & $\downarrow Z E B 1$ & N/A & $\begin{array}{l}\downarrow \text { migration } \\
\text { and invasion }\end{array}$ & [116] \\
\hline Lung cancer & VPA & $\begin{array}{l}\text { A549 cells } \\
\text { in vitro }\end{array}$ & $\begin{array}{l}\text { cells treated with VPA vs. } \\
\text { untreated cells }\end{array}$ & $\uparrow$ & $\mathrm{N} / \mathrm{A}$ & N/A & N/A & $\mathrm{N} / \mathrm{A}$ & $\begin{array}{l}\text { reduction of } \\
\text { spindle-like } \\
\text { morphology }\end{array}$ & N/A & [117] \\
\hline $\begin{array}{l}\text { Hepatocellular } \\
\text { carcinoma }\end{array}$ & TSA & $\begin{array}{l}\text { HepG2 cells, } \\
\text { Huh7 cells } \\
\text { in vitro }\end{array}$ & $\begin{array}{l}\text { cells treated with TSA vs. untreated } \\
\text { cells }\end{array}$ & $\downarrow$ & N/A & $\uparrow$ & $\uparrow$ & $\uparrow S N A I L, T W I S T$ & $\mathrm{~N} / \mathrm{A}$ & $\begin{array}{l}\uparrow \text { migration } \\
\text { and invasion }\end{array}$ & [120] \\
\hline $\begin{array}{l}\text { Hepatocellular } \\
\text { carcinoma }\end{array}$ & VPA & $\begin{array}{l}\text { HepG2 cells, } \\
\text { Huh7 cells } \\
\text { in vitro }\end{array}$ & $\begin{array}{l}\text { cells treated with VPA vs. } \\
\text { untreated cells }\end{array}$ & $\downarrow$ & N/A & $\uparrow$ & $\uparrow$ & $\uparrow S N A I L, T W I S T$ & N/A & $\begin{array}{c}\uparrow \text { migration } \\
\text { and invasion }\end{array}$ & [120] \\
\hline $\begin{array}{l}\text { Hepatocellular } \\
\text { carcinoma }\end{array}$ & SAHA & $\begin{array}{l}\text { HepG2 cells } \\
\text { in vitro }\end{array}$ & $\begin{array}{l}\text { cells treated with SAHA vs. } \\
\text { untreated cells }\end{array}$ & $\downarrow$ & $\mathrm{N} / \mathrm{A}$ & $\uparrow$ & $\uparrow$ & $\uparrow S N A I L, T W I S T$ & N/A & $\begin{array}{c}\uparrow \text { migration } \\
\text { and invasion }\end{array}$ & [120] \\
\hline $\begin{array}{l}\text { Hepatocellular } \\
\text { carcinoma }\end{array}$ & MS-275 & $\begin{array}{l}\text { HepG2 cells } \\
\text { in vitro }\end{array}$ & $\begin{array}{l}\text { cells treated with MS-275 vs. } \\
\text { untreated cells }\end{array}$ & $\downarrow$ & N/A & $\uparrow$ & $\uparrow$ & $\uparrow S N A I L, T W I S T$ & N/A & $\begin{array}{c}\uparrow \text { migration } \\
\text { and invasion }\end{array}$ & [120] \\
\hline $\begin{array}{l}\text { Hepatocellular } \\
\text { carcinoma }\end{array}$ & SAHA & $\begin{array}{l}\text { HepG2 cells, } \\
\text { QGY-7703 cells } \\
\text { in vitro; mouse } \\
\text { in vivo }\end{array}$ & $\begin{array}{l}\text { cells treated with SAHA vs. } \\
\text { untreated cells }\end{array}$ & N/A & N/A & $\uparrow$ & $\uparrow$ & $\begin{array}{c}\uparrow S N A I L \text { through } \\
\text { SMAD2/3 } \\
\text { phosphorylation }\end{array}$ & $\begin{array}{c}\text { changes of } \\
\text { phenotype were } \\
\text { detected }\end{array}$ & $\uparrow$ invasion & [121] \\
\hline $\begin{array}{l}\text { Hepatocellular } \\
\text { carcinoma }\end{array}$ & $\mathrm{NaB}$ & $\begin{array}{c}\text { HepG2 } \\
\text { cells/QGY-7703 } \\
\text { cells in vitro; } \\
\text { mouse in vivo }\end{array}$ & $\begin{array}{l}\text { cells treated with } \mathrm{NaB} \text { vs. untreated } \\
\text { cells }\end{array}$ & $\mathrm{N} / \mathrm{A}$ & N/A & N/A & $\uparrow$ & $\begin{array}{c}\uparrow S N A I L \text { through } \\
\text { SMAD2/3 } \\
\text { phosphorylation }\end{array}$ & $\mathrm{N} / \mathrm{A}$ & †invasion & [121] \\
\hline $\begin{array}{l}\text { Hepatocellular } \\
\text { carcinoma }\end{array}$ & LBH589 & $\begin{array}{l}\text { HepG2 cells } \\
\text { in vitro }\end{array}$ & $\begin{array}{l}\text { cells treated with LBH589 vs. } \\
\text { untreated cells }\end{array}$ & $\uparrow$ & $\mathrm{N} / \mathrm{A}$ & $\downarrow$ & $\downarrow$ & $\downarrow$ TWIST1 & $\mathrm{N} / \mathrm{A}$ & $\downarrow$ invasion & [122] \\
\hline $\begin{array}{l}\text { Hepatocellular } \\
\text { carcinoma }\end{array}$ & RAS2410 & $\begin{array}{l}\text { Hep3B, HLE, } \\
\text { HLF cells } \\
\text { in vitro }\end{array}$ & $\begin{array}{l}\text { cells treated with RAS2410 vs. } \\
\text { untreated cells }\end{array}$ & $\uparrow$ & N/A & $\downarrow$ & $\downarrow$ & $\rightarrow$ TWIST, SNAI1 & N/A & $\begin{array}{l}\downarrow \text { migration } \\
\text { and invasion }\end{array}$ & [123] \\
\hline
\end{tabular}


Table 2. Cont

\begin{tabular}{|c|c|c|c|c|c|c|c|c|c|c|c|}
\hline Type of Cancer & $\begin{array}{c}\text { HDI } \\
\text { (Individually or } \\
\text { in Combination) }\end{array}$ & $\begin{array}{l}\text { Experimental } \\
\text { Model }\end{array}$ & Type of Treatment & E-cadherin & B-catenin & $\mathrm{N}$-cadherin & Vimentin & $\begin{array}{l}\text { Transcription } \\
\text { Factors }\end{array}$ & $\begin{array}{l}\text { Changes in } \\
\text { Morphology }\end{array}$ & $\begin{array}{l}\text { Migration and } \\
\text { Invasion }\end{array}$ & Ref. \\
\hline Cholangiocarcinoma & VPA & $\begin{array}{l}\text { HuCC-T1 cells } \\
\text { in vitro }\end{array}$ & $\begin{array}{l}\text { cells treated with VPA vs. } \\
\text { untreated cells }\end{array}$ & $\rightarrow$ & N/A & $\mathrm{N} / \mathrm{A}$ & $\rightarrow$ & $\mathrm{N} / \mathrm{A}$ & no changes & $\begin{array}{l}\downarrow \text { migration } \\
\text { and invasion }\end{array}$ & [124] \\
\hline Cholangiocarcinoma & TSA & $\begin{array}{l}\text { HuCC-T1 cells } \\
\text { in vitro }\end{array}$ & $\begin{array}{l}\text { cells treated with TSA vs. untreated } \\
\text { cells }\end{array}$ & $\uparrow$ & $\mathrm{N} / \mathrm{A}$ & $\mathrm{N} / \mathrm{A}$ & $\uparrow$ & $\mathrm{N} / \mathrm{A}$ & no changes & $\begin{array}{l}\downarrow \text { migration } \\
\text { and invasion }\end{array}$ & [124] \\
\hline Cholangiocarcinoma & $\begin{array}{c}\mathrm{VPA}+ \\
\text { gemcitabine }\end{array}$ & $\begin{array}{l}\text { HuCC-T1 cells } \\
\text { in vitro }\end{array}$ & $\begin{array}{l}\text { cells treated with VPA and } \\
\text { gemcitabine vs. cells treated } \\
\text { gemcitabine }\end{array}$ & $\uparrow$ & N/A & $\mathrm{N} / \mathrm{A}$ & $\uparrow$ & N/A & $\begin{array}{l}\text { from spindle to } \\
\text { rectangular caused } \\
\text { by gemcitabine }\end{array}$ & $\begin{array}{l}\downarrow \text { migration } \\
\text { and invasion }\end{array}$ & [124] \\
\hline Cholangiocarcinoma & TSA + gemcitabine & $\begin{array}{l}\text { HuCC-T1 cells } \\
\text { in vitro }\end{array}$ & $\begin{array}{l}\text { cells treated with TSA and } \\
\text { gemcitabine vs. cells treated } \\
\text { gemcitabine }\end{array}$ & $\uparrow$ & N/A & $\mathrm{N} / \mathrm{A}$ & $\uparrow$ & N/A & $\begin{array}{l}\text { from spindle to } \\
\text { rectangular caused } \\
\text { by gemcitabine }\end{array}$ & $\begin{array}{l}\downarrow \text { migration } \\
\text { and invasion }\end{array}$ & [124] \\
\hline Pancreatic cancer & $4 S C-202$ & $\begin{array}{l}\text { Panc1 cells } \\
\text { L3.6 cells } \\
\text { in vitro }\end{array}$ & $\begin{array}{l}\text { TGF- } \beta 1 \text { pretreated Panc1 cells } \\
\text { treated with } 4 \text { SC- } 202 \text { vs. untreated } \\
\text { cells in vitro; mice with implanted } \\
\text { L3.6 cells in vivo }\end{array}$ & $\downarrow$ & N/A & $\uparrow$ & $\downarrow$ & $\downarrow Z E B 1$, SNAIL1 & N/A & N/A & [125] \\
\hline Pancreatic cancer & BSI & $\begin{array}{l}\text { Panc1 cells } \\
\text { in vitro }\end{array}$ & $\begin{array}{l}\text { Panc1 cells treated with BSI vs. } \\
\text { untreated cells in vitro }\end{array}$ & $\uparrow$ & $\mathrm{N} / \mathrm{A}$ & $\downarrow$ & N/A & $\downarrow S N A I L$ & $\begin{array}{l}\text { tumor spheres } \\
\text { formation is } \\
\text { unchanged but their } \\
\text { size is significantly } \\
\text { decreased }\end{array}$ & $\begin{array}{l}\downarrow \text { migration } \\
\text { and invasion }\end{array}$ & [126] \\
\hline Pancreatic cancer & $\begin{array}{l}\text { MGCD103+ } \\
\text { gemcitabine }\end{array}$ & $\begin{array}{l}\text { Panc1 cells, } \\
\text { hPaca-1 } \\
\text { derived tumor } \\
\text { cells in vitro }\end{array}$ & $\begin{array}{l}\text { Panc1 cells, hPaca-1 derived tumor } \\
\text { cells treated with MGCD103 and } \\
\text { gemcitabine vs. gemcitabine } \\
\text { treated cells in vitro }\end{array}$ & $\uparrow$ & $\mathrm{N} / \mathrm{A}$ & $\mathrm{N} / \mathrm{A}$ & N/A & $\downarrow Z E B 1$ & N/A & N/A & [127] \\
\hline Pancreatic cancer & SAHA & $\begin{array}{l}\text { Pancreatic } \\
\text { CSCs }\end{array}$ & $\begin{array}{l}\text { pancreatic CSCs treated with } \\
\text { SAHA vs. untreated cells in vitro }\end{array}$ & $\uparrow$ & N/A & $\downarrow$ & N/A & $\begin{array}{l}\downarrow Z E B, \text { SNAIL, } \\
\quad \text { SLUG }\end{array}$ & N/A & $\downarrow$ invasion & [12] \\
\hline Colorectal cancer & TSA & $\begin{array}{l}\text { SW480 cells } \\
\text { in vitro }\end{array}$ & $\begin{array}{l}\text { cells treated with TSA vs. untreated } \\
\text { cells }\end{array}$ & $\uparrow$ & $\mathrm{N} / \mathrm{A}$ & $\mathrm{N} / \mathrm{A}$ & $\downarrow$ & $\downarrow S L U G$ & N/A & $\begin{array}{l}\downarrow \text { migration } \\
\text { and invasion }\end{array}$ & [121] \\
\hline Colorectal cancer & VPA & $\begin{array}{l}\text { SW } 480 \text { cells } \\
\text { in vitro }\end{array}$ & $\begin{array}{l}\text { cells treated with VPA vs. } \\
\text { untreated cells }\end{array}$ & $\downarrow$ & N/A & $\uparrow$ & $\uparrow$ & $\uparrow S N A I L$ & N/A & $\begin{array}{c}\uparrow \text { migration } \\
\text { and invasion }\end{array}$ & [128] \\
\hline Colorectal cancer & VPA & $\begin{array}{l}\text { HCT116 cells } \\
\text { in vitro }\end{array}$ & $\begin{array}{l}\text { cells treated with VPA vs. } \\
\text { untreated cells }\end{array}$ & $\downarrow$ & N/A & $\uparrow$ & $\uparrow$ & $\uparrow S N A I L$ & N/A & $\begin{array}{l}\uparrow \text { migration } \\
\text { and invasion }\end{array}$ & [128] \\
\hline Colorectal cancer & Compound 11 & $\begin{array}{l}\text { HCT116 cells } \\
\text { in vitro }\end{array}$ & $\begin{array}{l}\text { cells treated with compound } 11 \text { vs. } \\
\text { untreated cells }\end{array}$ & $\uparrow$ & $\downarrow$ & $\downarrow$ & $\downarrow$ & $\mathrm{N} / \mathrm{A}$ & N/A & $\downarrow$ migration & [129] \\
\hline Colorectal cancer & Compound 11 & $\begin{array}{l}\text { HT29 cells } \\
\text { in vitro }\end{array}$ & $\begin{array}{l}\text { cells treated with compound } 11 \text { vs. } \\
\text { untreated cells }\end{array}$ & $\mathrm{N} / \mathrm{A}$ & N/A & $\mathrm{N} / \mathrm{A}$ & $\mathrm{N} / \mathrm{A}$ & N/A & N/A & $\downarrow$ migration & [129] \\
\hline Colorectal cancer & Compound 11 & $\begin{array}{c}\text { HCT116 } \\
\text { xenograft } \\
\text { model in vivo }\end{array}$ & $\begin{array}{l}\text { mice treated compound } 11 \mathrm{vs.} \\
\text { untreated mice }\end{array}$ & $\uparrow$ & N/A & $\downarrow$ & $\downarrow$ & N/A & N/A & $\downarrow$ migration & [129] \\
\hline
\end{tabular}


Table 2. Cont

\begin{tabular}{|c|c|c|c|c|c|c|c|c|c|c|c|}
\hline Type of Cancer & $\begin{array}{c}\text { HDI } \\
\text { (Individually or } \\
\text { in Combination) }\end{array}$ & $\begin{array}{l}\text { Experimental } \\
\text { Model }\end{array}$ & Type of Treatment & E-cadherin & B-catenin & $\mathrm{N}$-cadherin & Vimentin & $\begin{array}{l}\text { Transcription } \\
\text { Factors }\end{array}$ & $\begin{array}{l}\text { Changes in } \\
\text { Morphology }\end{array}$ & $\begin{array}{l}\text { Migration and } \\
\text { Invasion }\end{array}$ & Ref. \\
\hline Colorectal cancer & TSA & $\begin{array}{l}\text { HT29, SW480, } \\
\text { DLD1, HTC116 } \\
\text { cells in vitro }\end{array}$ & $\begin{array}{l}\text { cells treated with TSA vs. untreated } \\
\text { cells }\end{array}$ & $\downarrow$ & N/A & N/A & $\uparrow$ & $\mathrm{N} / \mathrm{A}$ & $\begin{array}{l}\text { altered to spindle } \\
\text { like morphology }\end{array}$ & $\begin{array}{l}\rightarrow \text { migration, } \\
\uparrow \text { invasion only } \\
\text { in DLD1 cells }\end{array}$ & [15] \\
\hline Colorectal cancer & VPA & $\begin{array}{l}\text { HT29, SW480, } \\
\text { DLD1, HTC116 } \\
\text { cells in vitro }\end{array}$ & $\begin{array}{l}\text { cells treated with VPA vs. } \\
\text { untreated cells }\end{array}$ & $\downarrow$ & N/A & N/A & $\uparrow$ & N/A & $\begin{array}{l}\text { altered to spindle } \\
\text { like morphology }\end{array}$ & $\begin{array}{l}\rightarrow \text { migration, } \\
\text { †invasion in } \\
\text { DLD1 and } \\
\text { SW480 cells }\end{array}$ & [15] \\
\hline Colorectal cancer & TGF- $\beta 1$ & $\begin{array}{l}\text { HT29, SW480, } \\
\text { DLD1, HTC116 } \\
\text { cells in vitro }\end{array}$ & $\begin{array}{l}\text { cells treated with TGF- } \beta 1 \text { vs. } \\
\text { untreated cells }\end{array}$ & $\downarrow$ & $\mathrm{N} / \mathrm{A}$ & $\mathrm{N} / \mathrm{A}$ & $\uparrow$ & $\mathrm{N} / \mathrm{A}$ & $\begin{array}{l}\text { altered to spindle } \\
\text { like morphology }\end{array}$ & $\begin{array}{l}\text { †invasion only } \\
\text { in DLD1 cells }\end{array}$ & [15] \\
\hline Colorectal cancer & TSA+ TGF- $\beta 1$ & $\begin{array}{l}\text { HT29, SW480, } \\
\text { DLD1, HTC116 } \\
\text { cells in vitro }\end{array}$ & $\begin{array}{l}\text { cells treated with TSA and TGF- } \beta 1 \\
\text { vs. untreated cells }\end{array}$ & $\downarrow$ & N/A & N/A & $\uparrow$ & N/A & $\begin{array}{l}\text { altered to spindle } \\
\text { like morphology }\end{array}$ & $\begin{array}{c}\text { HT29 N/A, } \\
\text { SW480 } \\
\uparrow \text { migration, } \\
\text { LDL1 } \\
\rightarrow \text { invasion, } \\
\text { HTC116 N/A }\end{array}$ & [15] \\
\hline Colorectal cancer & VPA + TGF- $\beta 1$ & $\begin{array}{l}\text { HT29, SW480, } \\
\text { DLD1, HTC116 } \\
\text { cells in vitro }\end{array}$ & $\begin{array}{l}\text { cells treated with VPA and TGF- } \beta 1 \\
\text { vs. untreated cells }\end{array}$ & $\downarrow$ & $\mathrm{N} / \mathrm{A}$ & $\mathrm{N} / \mathrm{A}$ & $\uparrow$ & $\mathrm{N} / \mathrm{A}$ & $\begin{array}{l}\text { altered to spindle } \\
\text { like morphology }\end{array}$ & $\begin{array}{c}\text { HT29 N/A, } \\
\text { SW480 } \\
\uparrow \text { migration, } \\
\text { LDL1 } \\
\uparrow \text { migration, } \\
\rightarrow \text { invasion, } \\
\text { HTC116 N/A }\end{array}$ & [15] \\
\hline Renal cancer & VPA & $\begin{array}{l}\text { Renca cells } \\
\text { in vitro, mice } \\
\text { in vivo }\end{array}$ & $\begin{array}{l}\text { cells treated with VPA vs. } \\
\text { untreated cells }\end{array}$ & $\downarrow$ & $\downarrow$ & N/A & $\downarrow$ & $\begin{array}{c}\uparrow T W I S T 1, \\
\downarrow \text { TWIST2 } \\
\rightarrow \text { SNAIL1, } \\
\text { SNAIL2 }\end{array}$ & $\begin{array}{l}\text { interspace between } \\
\text { cells after HDIs } \\
\text { treatment }\end{array}$ & $\downarrow$ migration & [130] \\
\hline Renal cancer & MS-275 & $\begin{array}{l}\text { Renca cells } \\
\text { in vitro, mice } \\
\text { in vivo }\end{array}$ & $\begin{array}{l}\text { cells treated with MS-275 vs. } \\
\text { untreated cells }\end{array}$ & $\downarrow$ & $\downarrow$ & N/A & N/A & N/A & $\begin{array}{l}\text { interspace between } \\
\text { cells after HDIs } \\
\text { treatment }\end{array}$ & $\downarrow$ migration & [130] \\
\hline Renal cancer & TSA & $\begin{array}{l}\text { HK2 cells } \\
\text { in vitro }\end{array}$ & $\begin{array}{l}\text { TGF- } \beta 1 \text {-pretreated HK2 cells } \\
\text { treated with TSA vs. } \\
\text { TGF- } \beta 1 \text {-treated HK2 cells }\end{array}$ & $\uparrow$ & N/A & $\rightarrow$ & N/A & N/A & N/A & N/A & [131] \\
\hline Renal cancer & TSA & $\begin{array}{l}\text { RPTEC cells } \\
\text { in vitro }\end{array}$ & $\begin{array}{l}\text { TGF- } \beta 1 \text {-pretreated RPTEC cells } \\
\text { treated with TSA vs. untreated } \\
\text { RPTEC cells }\end{array}$ & $\uparrow$ & $\mathrm{N} / \mathrm{A}$ & $\mathrm{N} / \mathrm{A}$ & $\mathrm{N} / \mathrm{A}$ & $\begin{array}{l}\rightarrow S M A D 2 \\
\text { SMAD3 }\end{array}$ & $\begin{array}{l}\text { from cuboidal to } \\
\text { elongated form }\end{array}$ & $\mathrm{N} / \mathrm{A}$ & [131] \\
\hline
\end{tabular}


Table 2. Cont

\begin{tabular}{|c|c|c|c|c|c|c|c|c|c|c|c|}
\hline Type of Cancer & $\begin{array}{c}\text { HDI } \\
\text { (Individually or } \\
\text { in Combination) }\end{array}$ & $\begin{array}{l}\text { Experimental } \\
\text { Model }\end{array}$ & Type of Treatment & E-cadherin & B-catenin & $\mathrm{N}$-cadherin & Vimentin & $\begin{array}{l}\text { Transcription } \\
\text { Factors }\end{array}$ & $\begin{array}{l}\text { Changes in } \\
\text { Morphology }\end{array}$ & $\begin{array}{l}\text { Migration and } \\
\text { Invasion }\end{array}$ & Ref. \\
\hline Urothelial cancer & CDDP+SAHA & $\begin{array}{l}\text { RT-112 and } \\
\text { T-24 cells in } \\
\text { cell culture or } \\
\text { implanted on } \\
\text { the chicken } \\
\text { chorioallantoic } \\
\text { membrane } \\
\text { (CAM) }\end{array}$ & $\begin{array}{l}\text { cells implanted on the CAM treated } \\
\text { with CDDP + SAHA vs. cells } \\
\text { treated with CDDP }\end{array}$ & N/A & N/A & $\mathrm{N} / \mathrm{A}$ & $\mathrm{N} / \mathrm{A}$ & N/A & $\begin{array}{l}\text { CAM tumor } \\
\text { reduction }\end{array}$ & & [132] \\
\hline Urothelial cancer & $\mathrm{CDDP}+$ Romidepsin & $\begin{array}{l}\text { RT-112 and } \\
\text { T-24 cells in } \\
\text { cell culture or } \\
\text { implanted on } \\
\text { the chicken } \\
\text { chorioallantoic } \\
\text { membrane } \\
\text { (CAM) }\end{array}$ & $\begin{array}{l}\text { cells implanted on the CAM treated } \\
\text { CDDP+Romidepsin vs. cells } \\
\text { treated with CDDP }\end{array}$ & N/A & N/A & N/A & N/A & N/A & $\begin{array}{l}\text { CAM tumor } \\
\text { reduction }\end{array}$ & & [132] \\
\hline Prostate cancer & AR-42 & $\begin{array}{l}\text { Ace- } 1 \text { cells } \\
\text { in vitro }\end{array}$ & $\begin{array}{l}\text { cells treated with AR-42 vs. } \\
\text { untreated cells }\end{array}$ & $\downarrow$ & $\rightarrow$ & $\downarrow$ & $\rightarrow$ & $\begin{array}{c}\downarrow T W I S T, M Y O F, \\
\uparrow S N A I L, S L U G, \\
\text { PTEN, } \\
\text { FAK, ZEB1 }\end{array}$ & $\begin{array}{l}\text { reduction of spindle } \\
\text { like morphology }\end{array}$ & $\begin{array}{l}\downarrow \text { migration } \\
\text { and invasion }\end{array}$ & [133] \\
\hline Prostate cancer & AR- 42 & $\begin{array}{l}\text { nude mice } \\
\text { with implanted } \\
\text { Ace-1 cells } \\
\text { in vivo } \\
\end{array}$ & $\begin{array}{l}\text { mice with Ace-1 cells treated AR- } 42 \\
\text { vs. untreated mice }\end{array}$ & $\mathrm{N} / \mathrm{A}$ & $\mathrm{N} / \mathrm{A}$ & N/A & $\mathrm{N} / \mathrm{A}$ & $\mathrm{N} / \mathrm{A}$ & $\begin{array}{l}\text { irregular shape of } \\
\text { cell after AR42 } \\
\text { treatment }\end{array}$ & $\begin{array}{l}\downarrow \text { reduction of } \\
\quad \text { bone } \\
\text { metastasis }\end{array}$ & [133] \\
\hline Prostate cancer & $\begin{array}{l}\text { SAHA, TSA, } \\
\text { RGFP966 }\end{array}$ & $\begin{array}{l}\mathrm{LNCaP} \text { cells } \\
\text { in vitro }\end{array}$ & $\begin{array}{l}\text { cells treated with HDIs vs. } \\
\text { untreated cells }\end{array}$ & $\mathrm{N} / \mathrm{A}$ & $\mathrm{N} / \mathrm{A}$ & $\mathrm{N} / \mathrm{A}$ & $\begin{array}{c}\text { } \text { SAHA, } \\
\text { TSA; } \\
\rightarrow \text { RGFP966 }\end{array}$ & $\begin{array}{c}\downarrow N K X 1, \text { FOXA1; } \\
\uparrow S L U G, \text { ZEB1 } \\
\text { (SAHA, TSA), } \\
\rightarrow \text { SLUG, ZEB1 } \\
\text { (RGFP66) }\end{array}$ & N/A & $\begin{array}{c}\uparrow \text { migration } \\
\text { (SAHA), N/A } \\
\text { (TSA), } \\
\rightarrow \text { migration } \\
\text { (RGFP99) }\end{array}$ & [134] \\
\hline Prostate cancer & TSA & $\begin{array}{c}\text { PC3 cells } \\
\text { in vitro }\end{array}$ & $\begin{array}{l}\text { cells treated with TSA vs. untreated } \\
\text { cells }\end{array}$ & $\uparrow$ & $\mathrm{N} / \mathrm{A}$ & $\mathrm{N} / \mathrm{A}$ & $\downarrow$ & $\downarrow S L U G$ & N/A & $\begin{array}{l}\downarrow \text { migration } \\
\text { and invasion }\end{array}$ & [13] \\
\hline Prostate cancer & VPA & $\begin{array}{l}\text { PC3 cells } \\
\text { in vitro }\end{array}$ & $\begin{array}{l}\text { cells treated with VPA vs. } \\
\text { untreated cells }\end{array}$ & $\uparrow$ & N/A & N/A & N/A & N/A & N/A & $\downarrow$ migration & [11] \\
\hline Breast cancer & SAHA & $\begin{array}{l}\text { MzChA-1 and } \\
\text { TFK- } 1 \text { cells } \\
\text { in vitro }\end{array}$ & $\begin{array}{c}\text { cells treated with SAHA pretreated } \\
\text { with TGF- } \beta 1 \text { vs. cells treated with } \\
\text { TGF- } \beta 1\end{array}$ & $\uparrow$ & N/A & $\downarrow$ & $\downarrow$ & $\begin{array}{c}\text { inhibition of } \\
p-S M A D 2, \\
p-S M A D 3 \text { and } \\
S M A D 4 \text { nuclear } \\
\text { translocation } \\
\text { induced by } \\
\text { TGF- } \beta 1\end{array}$ & $\begin{array}{l}\text { reduction of changes } \\
\text { from valvate-like- to } \\
\text { spindle-like shapes } \\
\text { caused by TGF- } \beta 1\end{array}$ & $\mathrm{~N} / \mathrm{A}$ & [135] \\
\hline
\end{tabular}


Table 2. Cont

\begin{tabular}{|c|c|c|c|c|c|c|c|c|c|c|c|}
\hline Type of Cancer & $\begin{array}{c}\text { HDI } \\
\text { (Individually or } \\
\text { in Combination) }\end{array}$ & $\begin{array}{l}\text { Experimental } \\
\text { Model }\end{array}$ & Type of Treatment & E-cadherin & B-catenin & $\mathrm{N}$-cadherin & Vimentin & $\begin{array}{l}\text { Transcription } \\
\text { Factors }\end{array}$ & $\begin{array}{l}\text { Changes in } \\
\text { Morphology }\end{array}$ & $\begin{array}{l}\text { Migration and } \\
\text { Invasion }\end{array}$ & Ref. \\
\hline Breast cancer & SAHA & $\begin{array}{l}\text { MDA-MB-231 } \\
\text { and BT-549 } \\
\text { cells in vitro }\end{array}$ & $\begin{array}{l}\text { cells treated with SAHA vs. } \\
\text { untreated cells }\end{array}$ & $\downarrow$ & N/A & $\uparrow$ & $\uparrow$ & $\begin{array}{c}\rightarrow \text { SNAIL, SLUG, } \\
\text { TWIST and ZEB } \\
\text { expression and } \\
\text { translocation }\end{array}$ & N/A & $\uparrow$ migration & [136] \\
\hline Breast cancer & SAHA, VPA & $\begin{array}{l}\text { MDA-MB-231 } \\
\text { and SUM159 } \\
\text { cells in vitro }\end{array}$ & $\begin{array}{l}\text { ed with VPA or SAHA vs. } \\
\text { untreated cells }\end{array}$ & $\begin{array}{c}\text { not } \\
\text { detected }\end{array}$ & $\mathrm{N} / \mathrm{A}$ & $\uparrow$ & $\uparrow$ & $\begin{array}{c}\downarrow \text { \FOXC3, ZEB1 } \\
\uparrow \text { SNAIL2, TWIST1 }\end{array}$ & $\uparrow$ sphere formation & $\uparrow$ migration & [137] \\
\hline Breast cancer & LBH589 & $\begin{array}{l}\text { MDA-MB-231 } \\
\text { and BT-549 } \\
\text { cells in vitro }\end{array}$ & $\begin{array}{l}\text { cell treated with LBH589 vs. } \\
\text { untreated cells }\end{array}$ & $\uparrow$ & $\mathrm{N} / \mathrm{A}$ & $\downarrow$ & $\downarrow$ & $\downarrow Z E B 1, Z E B 2$ & $\begin{array}{l}\text { more epithelial } \\
\text { phenotype }\end{array}$ & $\begin{array}{l}\downarrow \text { migration } \\
\text { and invasion }\end{array}$ & [138] \\
\hline Breast cancer & LBH589 & $\begin{array}{l}\text { MCF7 cells } \\
\text { in vitro }\end{array}$ & $\begin{array}{l}\text { cell treated with LBH589 vs. } \\
\text { untreated cells }\end{array}$ & $\rightarrow$ & $\mathrm{N} / \mathrm{A}$ & $\mathrm{N} / \mathrm{A}$ & $\rightarrow$ & $\rightarrow Z E B 1, Z E B 2$ & $\begin{array}{l}\text { more epithelial } \\
\text { phenotype }\end{array}$ & $\begin{array}{l}\downarrow \text { migration } \\
\text { and invasion }\end{array}$ & [138] \\
\hline Breast cancer & MS-275 & $\begin{array}{l}\text { MDA-MB-231 } \\
\text { and Hs578T } \\
\text { cells in vitro }\end{array}$ & $\begin{array}{l}\text { cells treated with MS-275 vs. } \\
\text { untreated cells }\end{array}$ & $\uparrow$ & N/A & $\downarrow$ & $\downarrow$ & $\downarrow$ SNAIL, TWIST & $\begin{array}{l}\text { more epithelial } \\
\text { phenotype }\end{array}$ & $\downarrow$ migration & [14] \\
\hline Breast cancer & MS-275 & $\begin{array}{l}\text { Balb c nude } \\
\text { mice } \\
\text { implanted } \\
\text { with TRAIL } \\
\text { resistant } \\
\text { MDA-MB-468 } \\
\text { cells in vivo }\end{array}$ & $\begin{array}{l}\text { mice treated MS-275 vs. untreated } \\
\text { mice }\end{array}$ & $\uparrow$ & $\mathrm{N} / \mathrm{A}$ & $\mathrm{N} / \mathrm{A}$ & $\downarrow$ & $\begin{array}{l}\downarrow Z E B 1, \text { SNAIL, } \\
\quad \text { SLUG }\end{array}$ & N/A & N/A & [139] \\
\hline Breast cancer & MS-275+TRAIL & $\begin{array}{l}\text { Balb c nude } \\
\text { mice } \\
\text { implanted } \\
\text { with TRAIL } \\
\text { resistant } \\
\text { MDA-MB-468 } \\
\text { cells in vivo }\end{array}$ & $\begin{array}{l}\text { mice treated MS-275+TRAIL vs. } \\
\text { mice treated TRAIL only }\end{array}$ & $\uparrow$ & N/A & $\mathrm{N} / \mathrm{A}$ & $\downarrow$ & $\begin{array}{l}\downarrow Z E B 1, \text { SNAIL, } \\
\quad \text { SLUG }\end{array}$ & N/A & $\mathrm{N} / \mathrm{A}$ & [139] \\
\hline Ovarian cancer & TSA & $\begin{array}{l}\text { SKOV3 cells } \\
\text { in vitro }\end{array}$ & $\begin{array}{l}\text { cells treated with TSA vs. untreated } \\
\text { cells }\end{array}$ & $\downarrow$ & N/A & $\mathrm{N} / \mathrm{A}$ & $\downarrow$ & $\mathrm{N} / \mathrm{A}$ & N/A & $\downarrow$ migration & [140] \\
\hline Ovarian cancer & TSA+cisplatin & $\begin{array}{l}\text { SKOV3 cells } \\
\text { in vitro }\end{array}$ & $\begin{array}{l}\text { cells treated with TSA + cisplatin } \\
\text { vs. untreated cells }\end{array}$ & $\downarrow$ & N/A & $\mathrm{N} / \mathrm{A}$ & $\downarrow$ & N/A & N/A & $\downarrow$ migration & [140] \\
\hline Ovarian cancer & TSA+cisplatin & $\begin{array}{l}\text { Mice with HEY } \\
\text { injected cells } \\
\text { in vivo }\end{array}$ & $\begin{array}{l}\text { mice treated with cisplatin } \\
\text { followed by TSA vs. untreated mice }\end{array}$ & $\uparrow$ & N/A & N/A & $\downarrow$ & $\begin{array}{l}\downarrow \text { SNAIL, SLUG, } \\
\quad \text { TWIST }\end{array}$ & N/A & N/A & [140] \\
\hline
\end{tabular}


Table 2. Cont

\begin{tabular}{|c|c|c|c|c|c|c|c|c|c|c|c|}
\hline Type of Cancer & $\begin{array}{c}\text { HDI } \\
\text { (Individually or } \\
\text { in Combination) }\end{array}$ & $\begin{array}{l}\text { Experimental } \\
\text { Model }\end{array}$ & Type of Treatment & E-cadherin & B-catenin & $\mathrm{N}$-cadherin & Vimentin & $\begin{array}{l}\text { Transcription } \\
\text { Factors }\end{array}$ & $\begin{array}{l}\text { Changes in } \\
\text { Morphology }\end{array}$ & $\begin{array}{l}\text { Migration and } \\
\text { Invasion }\end{array}$ & Ref. \\
\hline $\begin{array}{l}\text { Head and neck } \\
\text { cancer }\end{array}$ & SAHA & $\begin{array}{l}\text { Hep-2 and KB } \\
\text { cells in vitro }\end{array}$ & $\begin{array}{l}\text { cells treated with SAHA vs. } \\
\text { untreated cells }\end{array}$ & $\uparrow$ & $\uparrow$ & $\mathrm{N} / \mathrm{A}$ & $\downarrow$ & N/A & $\begin{array}{l}\text { reduction of the } \\
\text { spindle like } \\
\text { morphology }\end{array}$ & $\begin{array}{l}\downarrow \text { migration } \\
\text { and invasion }\end{array}$ & [141] \\
\hline $\begin{array}{l}\text { Head and neck } \\
\text { cancer }\end{array}$ & VPA & $\begin{array}{c}\text { TE9 cells } \\
\text { pretreated with } \\
\text { TGF- } \beta 1 \text { or } \\
\text { irradiation } \\
\text { in vitro }\end{array}$ & $\begin{array}{l}\text { cells treated with VPA and TGF- } \beta 1 \\
\text { or irradiation before vs. cells } \\
\text { treated with TGF- } \beta 1 \text { or irradiation }\end{array}$ & $\uparrow$ & N/A & N/A & $\downarrow$ & $\begin{array}{c}\downarrow S M A D 2 \text { and } \\
\text { SMAD3 } \\
\text { phosphorylation, } \\
\downarrow T W I S T, S N A I L, \\
\text { SLUG }\end{array}$ & $\begin{array}{l}\text { reduction of spindle } \\
\text { like morphology } \\
\text { caused by TGF- } \beta 1 \text { or } \\
\text { irradiation }\end{array}$ & $\begin{array}{l}\downarrow \text { migration } \\
\text { and invasion }\end{array}$ & [142] \\
\hline Malignant glioma & LBH589+irradiation & $\begin{array}{l}\text { U251 cells } \\
\text { in vitro }\end{array}$ & $\begin{array}{c}\text { cells treated with } \\
\text { LBH589+irradiation vs. untreated } \\
\text { cells }\end{array}$ & $\uparrow$ & N/A & N/A & N/A & N/A & $\begin{array}{l}\text { reduction of } \\
\text { vasculogenic } \\
\text { mimicry formation }\end{array}$ & $\begin{array}{l}\downarrow \text { migration } \\
\text { and invasion }\end{array}$ & [143] \\
\hline
\end{tabular}

Abbreviations: $\uparrow$ increase, $\downarrow$ decrease, $\rightarrow$ no changes observed. SAHA-vorinostat, TSA-trichostatin A, VPA-valproic acid, MS-275 entinostat, NAB-sodium butyrate, LBH589-panobinostat, RAS2410-resminostat, 4SC-202-domatinostat, MGCD103-mocetinostat, compound 11-(E)-N-hydroxy-3-(1-(4-methoxyphenylsulfonyl)-1,2,3,4-tetrahydroquinolin-6-yl)acrylamide. 


\subsection{Hepatocellular Carcinoma}

TSA, VPA, SAHA and MS-275 have a strong positive influence on EMT, through decreasing E-cadherin expression and increasing N-cadherin expression in HepG2 cells. In turn, mesenchymal markers such as vimentin, TWIST and SNAIL become more abundant [120]. In the same vein, SAHA and sodium butyrate $(\mathrm{NaB})$ have been investigated as suppressors for cells proliferation in dose-dependent manner. Both of them significantly increase N-cadherin, vimentin, fibronectin and SNAIL expression in HepG2 cells. SNAIL upregulation is connected with phosphorylation of SMAD2/3 by these HDI. Additionally, SAHA and NaB are able to promote SNAIL and vimentin expression in xenografs [121]. Yet, panobinostat (LBH589) elevates E-cadherin expression in HCC-LM3 and HepG2 cells while decreases N-cadherin, vimentin and TWIST1 simultaneously [122]. Likewise, reminostat acts as an upregulator of E-cadherin expression and down-regulator of vimentin, TWIST1 and SNAIL in HLE cells [123] (Table 2).

\subsection{Cholangiocarcinoma}

VPA or TSA increased both E-cadherin and vimentin expression but inhibited invasion and migration of HuCC-T1 cholangiocarcinoma cells. Additionally, HuCC-T1 cells co-treated with gemcitabine and VPA or TSA showed higher E-cadherin, vimentin and ZO-1 levels as well as decreased migration and invasion.

Moreover, HuCC-T1 cells altered from spindle (mesenchymal phenotype) to rectangular (epithelial phenotype) shape after gemcitabine together with VPA or TSA treatments [124] (Table 2).

\subsection{Pancreatic Cancer}

HDAC inhibition by domatinostat (4SC-202) results in downregulation of E-cadherin with the concomitant upregulation of $\mathrm{N}$-cadherin in Panc-1 cells, but unexpectedly the downregulation of other mesenchymal markers such as ZEB1, SNAIL and vimentin, or TGF- $\beta$-induced SMAD2 phosphorylation. Likewise, it induces ZEB1 and SNAIL1 downregulation and CD24 upregulation in L3.6 and PxPC3 cells [125]. Conversely, (3R)-2-(biphenyl-4-ylsulfonyl)-1,2,3,4-tetrahydroisoquinoline-3-carboxylic acid (BSI) increases E-cadherin expression while decreases N-cadherin and SNAIL expression after 24h in Panc-1 cells. Interestingly, the level of E-cadherin remains unchanged, although the level of $\mathrm{N}$-cadherin and SNAIL was decreased in BxPC-3 cells after BSI treatment. Moreover, BSI is strongly associated with partial inhibition of invasion and migration in Panc-1 cells after $24 \mathrm{~h}$. BSI reduces tumor spheres formation in BxPC-3 cells, while in Panc-1 cells spheres formation is unchanged but their size was significantly decreased [126]. It has been found that another interesting agent, mocetinostat inhibits ZEB1 expression and increases E-cadherin and miR-203 upregulation in Panc-1 cells as well as in hPaca1-derived tumor cells. Paradoxically Panc-1-tumor xenografts grew bigger by mocetinostat treatment while the combination with gemcitabine resulted in a synergetic effect in tumor growth inhibition [127]. SAHA, on the other hand, inhibits proliferation in pancreatic CSCs. SAHA is able to increase miR-34a expression in pancreatic CSCs as well as in ASPC-1 and able to increase miR-34a expression in pancreatic CSCs as well as in ASPC-1 and MiaPaCa-2 cell lines. SAHA induces E-cadherin overexpression and $\mathrm{N}$-cadherin downregulation in pancreatic CSCs, simultaneously. Moreover, SAHA, as well as resveratrol, significantly downregulates ZEB1, SNAIL and SLUG expression in pancreatic CSCs. Additionally, resveratrol inhibited the invasion and migration of pancreatic CSCs. Resveratrol was able to inhibit the growth of pancreatic cancer in KrasG12D mice $[12,144]$ (Table 2).

\subsection{Colorectal Cancer}

TSA has been studied for its effects on SW480 colorectal cancer cells. TSA decreased the expression of SLUG, leading to the reversal of the EMT process and attenuation of invasion and migration of SW480 
cells. It has been suggested that TSA causes EMT reversion by increasing of E-cadherin and decreasing of vimentin expression [128]. Au contraire, treatment with VPA significantly stimulates migration and invasion in vitro, argubly by activation of EMT in HCT116 and SW480 human colorectal cancer cell lines, resulting in downregulating the epithelial markers: E-cadherin and ZO-1 and upregulating the mesenchymal markers: N-cadherin and fibronectin in both HCT116 and SW480 cells as well as upregulating the vimentin only in HCT116 cells. In line with this, VPA significantly promotes the expression of SNAIL via Akt/GSK-3b signal pathway. Suppression of SNAIL significantly reduced E-cadherin and increase of vimentin or fibronectin expression in both HCT116 and SW480 cells [128]. In fact, other HDIs also block EMT or induce MET, such as compound-11, who has also been found to induce MET in HCT116 and HT29 colorectal cancer cells, as well as in the HCT116 xenograft model. It has been observed that compound-11 induced downregulation of N-cadherin, vimentin and p-FAK (invasive marker), while E-cadherin was increased, through downregulation of Akt, which seems to be crucial for EMT in colorectal cancer cells [129]. Nevertheless, the oppsite has also been observed using TSA and VPA individually or in combination with TGF- $\beta 1$ in four colon carcinoma cell lines including: SI cells (DLD1 and HCT116) and MSS cells (HT29 and SW480). The results revealed that the morphological changes were similar pursuing TSA or VPA with or without TGF- $\beta 1$ co-treatment. CRC cell lines were altered to spindle-like morphology. Subsequent analyses showed a decrease in E-cadherin expression with TSA or VPA treatments in HCT116, DLD1 and SW480 cells. Vimentin was increased by treatment with the HDIs together with TGF- $\beta 1$ in the four carcinoma cell lines. Consistently, TSA or VPA induced increased cell migration and invasion abilities. All together, treatment by TSA or VPA in combination with TGF- $\beta 1$ seem to intensify EMT and migration in colon carcinoma cells. Moreover, in the MSS cells (HT29 and SW480) the EMT process was enhanced by TGF- $\beta 1$ and was much more intense than in the MSI cells (DLD1 and HCT116) [15] (Table 2).

\subsection{Renal Cancer}

VPA or MS-275 treatment resulted in cell morphology alternation and a reduction in migration of in Renca cells as compared to untreated Renca cells. At the molecular level, TWIST1 was upregulated and TWIST2 was downregulated after MS-275 treatment in time-dependent manner. Moreover, SNAIL2 expression was increased, while SNAIL1 expression was unchanged after $48 \mathrm{~h}$ of $5 \mu \mathrm{L}$ MS-275 treatment. Additionally, ZEB2 was significantly increased in dose-dependent manner, while ZEB1 remained unchanged after $48 \mathrm{~h}$ of MS-275 treatment. VPA and MS-275 hardly decrease $\beta$-catenin expression. Moreover, both of them upregulated E-cadherin levels after 48h. Interestingly, VPA significantly increased the growing rate of Renca cells resulting in phenotypical changes in cell morphology. Untreated Renca cells had a cobblestone-like morphology. HDIs treatment altered their morphology to a scattered pattern, with interspaces between cells. These cells displayed a star-shaped cell body resembling EMT-associated growth [130]. MS-275 as well as TSA significantly increased E-cadherin expression in TGF- $\beta 1$-treated HK2 cells. On the other hand, neither of them had no influence on $\mathrm{N}$-cadherin expression in the same cells [131]. Moreover, TSA increases E-cadherin expression without any effect on SMAD2 and SMAD3 phosphorylation in RPTEC cells [145]. PCI34051 resulted in no changes on N-cadherin and E-cadherin expression in HK2 cells. Finally, LMK235 was able to restore E-cadherin expression in HK2 cells, which is downregulated by TGF- $\beta 1$ [131] (Table 2).

\subsection{Urothelial Carcinoma}

The capacity of human urothelial cancer cell lines (UCCs) to form tumors after implantation on to the chicken chorioallantoic membrane (CAM) was examined. Both, RT-112 (epithelial-like) and T-24 (mesenchymal-like) urothelial cells generated tumors in the CAM model. RT-112 and T-24 cells in cell culture or as CAM tumors were treated with cisplatin alone or in combination with romidepsin or SAHA. Expression of E-cadherin (epithelial marker) and vimentin (mesenchymal marker) in untreated cells was similar in 2D cultures and CAM tumors. Cisplatin with HDIs reduced growth and weight of CAM tumors in a dose-dependent manner. HDIs treatment acted less efficiently in 2D cultures than in 
CAM model. Tumor size and weight were higher for RT-112 than T-24. Moreover, RT-112 tumors were more vascularized than T-24 tumors. RT-112 and T-24 CAM tumors were treated with $\mathrm{IC}_{25}$ and $\mathrm{IC}_{50}$ of cisplatin (CDDP) for 72 hours. Both weight and size of cisplatin-treated tumors were significantly reduced, especially in RT-112. Ki-67 mRNA expression in RT-112 cells was upregulated both in 2D cultures and CAM tumors after SAHA treatment. Downergulation of Ki-67 mRNA expression was observed in T-24 2D cultures treated with romidepsin or SAHA, but it was increased in HDIs-treated CAM tumors (Table 2) [132].

\subsection{Prostate Cancer}

AR-42 inhibited migration and invasion of Ace-1 cells caused apoptosis and decreased PCa cells bone metastasis. Moreover, AR-42 decreased E-cadherin, N-cadherin, TWIST, MYOF, and osteomimicry genes expression as well as anoikis (apoptosis induced by lack of correct cell/ECM attachment) resistance, while it increased SNAIL, PTEN, FAK and ZEB1 transcription factors expression in Ace- 1 cells. In addition, AR-42 downregulated the PCa metastasis to bone in nude mice. In addition, there has been observed an alteration of the spindle-like morphology to irregular shape of PCa cells, in both in vitro and in vivo conditions after AR42 treatment [133]. Furthermore, treatment with another HDI-SAHA-repressed EMT in LNCaP prostate cancer. It has been reported that SAHA downregulates FOXA1 expression. FOXA1 inhibits EMT in prostate cancer by decreased expression of SLUG transcription factor and repression of the neuroendocrine (NE) differentiation markers. SAHA also decreases NKX1 and PSA, which is another transcription factor and antigen, respectively. SAHA, like other pan-HDAC inhibitors (inter alia TSA), induces EMT by elevated protein levels such as SLUG, ZEB1 and vimentin. The same results were obtained using TSA treatment in LNCaP cells, however treatment with RGFP966, with the same panel of EMT markers was inefficient both in cell migration or invasion. SAHA and TSA induced cell migration, while RGFP966 was innocuous [134]. Treatment with LBH589 suppresses HMGA2 expression, decreases epithelial-mesenchymal plasticity in vitro and drastically decreases tumor growth and metastasis in vivo. Notably, in mice treated with LBH589 in combination with orchiectomy, there was an increase of p53 and androgen receptor (AR) acetylation, which in turn prevents the development of mCRPC and considerably extends life after castration [146]. In addition, TSA reverts EMT by a time-dependent upregulation of E-cadherin and downregulation of vimentin in PC3 prostate cancer cells. Moreover, TSA it has supressed SLUG expression which consequently prompted MET, as well as decreased cell invasion and migration abilities [13]. Likewise, VPA inhibited EMT by upregulation of the expression of E-cadherin, and concomitant suppression of the migration and invasion of prostate cancer cells [11] (Table 2).

\subsection{Breast Cancer}

SAHA inhibits EMT and chemoresistance induced by TGF- $\beta 1$ in MzChA- 1 and TFK-1 breast cancer cells. In both of these cell lines, TGF- $\beta 1$ caused morphological changes from valvate-like to spindle-like shapes, as well as downregulation of E-cadherin and upregulation of $\mathrm{N}$-cadherin, vimentin and SNAIL expression that the mechanism of SAHA's effect seems to be the inhibition of $p$-SMAD2, $p$-SMAD3 and SMAD4 nuclear translocation induced by TGF- $\beta 1$ in MzChA-1 cells, as well as the attenuation of the binding affinity of SMAD4 to the E-cadherin-related TWIST, SNAIL, SLUG, ZEB1 and ZEB2 transcription factors [135]. Yet, SAHA can promote migration and EMT via HDAC8/FOXA1 signals in MDA-MB-231 and BT-549 breast cancer cells. SAHA significantly downregulated the expression of E-cadherin and upregulated the mesenchymal markers: N-cadherin, vimentin and fibronectin. However, SAHA had no effect on the nuclear translocation or expression of SNAIL, SLUG, TWIST and ZEB [136]. MDA-MB-231, BT-549 and MCF-7 breast cancer cells were incubated with LBH589, another HDI, and examined for changes in cell morphology, migration and invasion in vitro. LBH589 reversed EMT, measured by the altered morphology and gene expression of triple negative breast cancer (TNBC). E-cadherin expression was significantly upregulated by LBH589 treatment in the two TNBC lines (MDA-MB-231 and BT-549), while no change was observed in the ER-positive 
(MCF-7) cells. Additionally, expression of ZEB1 and ZEB2 were significantly inhibited upon LBH589 treatment in both the MDA-MB-231 and BT-549 TNBC cell lines, while no changes were detected in the MCF-7 cells. The above-described alterations in EMT gene expression correlated with diminished cell migration and invasion in TNBC cells in vitro, as well as meaningful inhibition of TNBC cell metastasis to lung and brain in a xenograft model [138]. Treatment of MDA-MB-231 and Hs578T cells with entinostat (ENT) caused upregulation of $C D H 1$ and downregulation of $C D H 2$ and VIM mRNA expression. Moreover, chromatin immunoprecipitation (ChIP) assay revealed that the treatment of MDA-MB-231 and Hs578T cells with ENT increased the reduced the association of SNAIL and TWIST to the CDH1 promoter and downregulated both the SNAIL and TWIST expression which resulted in higher E-cadherin expression. Moreover, ENT inhibited migration of MDA-MB-231 and Hs578T breast cancer cells and induced MET [14]. The HDAC1 and HDAC3 inhibitor-MS-27-sensitized tumor necrosis factor-related apoptosis-inducing ligand (TRAIL)-resistant breast cancer MDA-MB-468 cells, inhibited angiogenesis and metastasis, and reversed EMT in vivo in xenografted BALB/c nude mice. MS-275 upregulated the expression of E-cadherin and downregulated the expression of $\mathrm{N}$-cadherin, as well as ZEB1, SNAIL and SLUG transcription factors in tumor tissues. Treatment of mice with TRAIL alone had no effect on the expression of these markers. Co-treatment of MDA-MB-468 cells with MS-275 and TRAIL had similar effects to those of MS-275 [139]. Yet, it is in breast cancer where contradicting data exist. For example, SUM159 and MDA-231 cells treated with VPA or SAHA become more stem-like by dedifferentiation. These dedifferentiated cells have a higher migration potential and are more resistant to taxol. HDIs-treated cells presented upregulation of several mesenchymal markers such as vimentin, $\mathrm{N}$-cadherin, fibronectin and tenascin- $\mathrm{C}$ while epithelial marker E-cadherin was not detected. Yet, several other mesenchymal markers such as SNAIL (after SAHA treatment), FOXC2 and ZEB1 (after SAHA and VPA treatment) were downregulated. HDACs inhibition resulted in the activation of the Wnt/ $\beta$-catenin signaling, which seems to be responsible for these phenotypical changes [137] (Table 2).

\subsection{Ovarian Cancer}

Effects of TSA alone or in combination with cisplatin were investigated in SKOV3 cell line in vitro. SKOV3 cells showed downregulation of both E-cadherin and $\mathrm{N}$-cadherin with exposure to TSA alone or in combination with cisplatin. Moreover, mouse xenografts were used to assess the anti-cancer activity of sequential cisplatin followed by TSA treatment. Such treatment significantly suppresses tumorigenicity of HEY xenografts through downregulation of N-cadherin and Snail, Slug, Twist transcription factors, as well as upregulation of E-cadherin expression [140] (Table 2).

\subsection{Head and Neck Cancer}

In gefitinib-resistant Hep-2 and KB squamous cell carcinoma of head and neck cells, SAHA reverted EMT by a time-dependent upregulation of E-cadherin and $\beta$-catenin and downregulation of vimentin. Moreover, there has been observed a reduction of the spindle-like morphology, characteristic for mesenchymal cells, with the acquisition of epithelial morphology, in both Hep-2 and KB cells after SAHA treatment [141]. VPA also induced a reversal of the mesenchymal phenotype caused by TGF- $\beta 1$ or irradiation in TE9 cancer cells, resulting in an increase of cell migration and invasion. TE9 cancer cells pre-treated with VPA exhibited less inhibition of E-cadherin expression and no increase of vimentin expression as compared with untreated cells stimulated by TGF- $\beta 1$ or irradiation. VPA inhibited the phosphorylation of SMAD2 and SMAD3 and downregulated TWIST, SNAIL, and SLUG transcription factors expression which previously were increased by TGF- $\beta 1$ or irradiation stimulation [142] (Table 2).

\subsection{Malignant Glioma}

Panobinostat (LBH589) combined with temozolomide and irradiation stimulation significantly decreased vasculogenic mimicry (VM) formation, migration and invasion as well as increased 
E-cadherin expression in U251 glioma cells compared with temozolomide and irradiation stimulation without LBH589 treatment [143] (Table 2).

\section{Discussion}

Virtually all HDIs block multiple HDACs, which in turn have each multiple protein targets and thus the resulting gene expression changes are not the direct targets of HDIs but rather the downstream effects lack of different HDACs activities. This is probably why in many cases both epithelial as well as mesenchymal markers increase in expression. Since each HDI has different HDAC targets, the downstream results might be substantially different depending on the expression of HDACs, their cellular roles, as well as the expression of other co-factors or orthogonal signaling pathways.

Since in tumor cells often epigenetically inactivate non-beneficial genes, while activate those that provide them with evolutionary advantages, changes in gene expression can result in a beneficial effect due to the re-expression of tumor suppressor [147] and the transcriptional silencing of pro-oncogenes [148,149]. Moreover, changes in acetylation of non-histone proteins might also provide beneficial in many cases, such as the reduction pro-oncogenic or pro-survival signaling pathways.

The search for inhibitors of single HDACs might provide us with a clearer picture of why there are contradictory results depending of the cell type. Also, there is need to understand the effects of HDIs in different cancer cells in light of their HDAC expression patterns and genomic, as well as epigenomic, landscapes.

While there is evidence that de-novo gene expression, in particular of epithelial-like genes, is a beneficial result for the treatment, this very effect of randomly re-opening chromatin might have two other effects: (1) turning on oncogenes or transposons, the latter related to the next point; and (2) genomic restructuring which might have effects in genomic stability. Genomic stability should be carefully considered in future studies using HDIs as long-term treatment with these drugs might result in genomic instability and acquisition of mutation in re-opened chromatin. There is evidence that such might occur, promoting more aggressive tumors [150]. This also prompts that the length of HDIs treatments should be carefully analysed.

\section{Conclusions}

HDACs play a pivotal role in the progression of cancers by reversible modulation of acetylation status of histone and non-histone proteins. However, the exact function of HDACs as a central mediator of tumorigenic capacity still remains unclear. There are abundant pre-clinical and clinical studies examining the effects of HDIs alone or in combination with other anti-cancer agents. The impact of HDIs on EMT differ greatly in various types of cancers (Table 3). VPA stimulates EMT in hepatocellular [120], breast [112] and colorectal cancers [128] while the same active agent inhibits this process in lung [117], prostate [11] and head and neck carcinomas [142]. Moreover, the impact of VPA on EMT in renal cancer is unclear. After VPA treatment expression both epithelial and mesenchymal markers decreased, moreover migration of renal cells was inhibited [130]. In lung [33,114,115] and breast cancers [14] most HDIs inhibited EMT with the exception of SAHA, which stimulated this process in both mentioned above types of cancer. LBH589 suppresses EMT in breast cancer [14] and hepatocellular carcinoma [122]. However, in hepatocellular carcinoma most of HDIs (VPA, SAHA, TSA, MS-275 [120], NaB [121]) stimulated EMT, excluding LBH589 [122] and RAS2410 [123] which inhibited this process. In head and neck cancer $[141,142]$ as well as prostate cancer all analyzed HDIs $[11,13]$ inhibited EMT. Existing data about the effects of HDIs on EMT are conflicting. Therefore, there is an urgent need to comprehensively study the mechanisms of action and role of HDIs on the EMT/MET processes in different cancer types at different stages of carcinogenesis. Side effects of application of these compounds also should be noted. More studies are needed to establish the best strategy to incorporate these agents into the therapy of patients with cancers, minimizing toxicity and maximizing clinical benefits. Clarification and validation of the detailed mechanisms of HDIs action will provide a bright future for the use of HDIs as one of the important tools in the fight against cancers. 
Table 3. The effect of histone deacetylase inhibitors (HDIs) on the epithelial-mesenchymal transition (EMT) process in tumors.

\begin{tabular}{|c|c|c|c|}
\hline HDI & 个EMT & $\downarrow$ EMT & Unclear Mechanism \\
\hline VPA & $\begin{array}{c}\text { Hepatocellular carcinoma [120], } \\
\text { breast [112], colorectal cancer } \\
{[128]}\end{array}$ & $\begin{array}{l}\text { Lung [117], prostate [11], head } \\
\text { and neck cancer [142] }\end{array}$ & Renal cancer [130] \\
\hline SAHA & $\begin{array}{l}\text { Hepatocellular carcinoma [120], } \\
\text { lung [118], breast cancer [136] }\end{array}$ & $\begin{array}{l}\text { Pancreatic [12], head and neck } \\
\text { cancer [141] }\end{array}$ & - \\
\hline TSA & $\begin{array}{l}\text { Hepatocellular carcinoma [120], } \\
\text { colorectal cancer [128] }\end{array}$ & $\begin{array}{c}\text { Lung }[114,115], \text { prostate cancer } \\
{[13]}\end{array}$ & $\begin{array}{c}\text { Cholangiocarcinoma [124], } \\
\text { ovarian cancer [140] }\end{array}$ \\
\hline MS-275 & Hepatocellular carcinoma [120] & Breast cancer [14] & Renal cancer [130] \\
\hline LBH589 & - & $\begin{array}{l}\text { Hepatocellular carcinoma [122], } \\
\text { breast cancer [14] }\end{array}$ & - \\
\hline RAS2410 & - & Hepatocellular carcinoma [123] & - \\
\hline 4SC-202 & - & - & Pancreatic cancer [125] \\
\hline AR-42 & - & - & Prostate cancer [133] \\
\hline $\mathrm{NaB}$ & Hepatocellular carcinoma [121] & - & - \\
\hline BSI & - & Pancreatic cancer [126] & - \\
\hline Compound 11 & - & Colorectal cancer [129] & - \\
\hline $\begin{array}{l}\text { Abbreviations: } \\
\text { VPA-valproic } \\
\text { RAS2410-resmin } \\
\text { 11-(E)-N-hydroxy }\end{array}$ & $\begin{array}{ccc} & \uparrow & \text { increase, } \quad \downarrow d e \\
\text { acid, } & \text { MS-275 entinosta } \\
\text { ostat, } & \text { 4SC-202-domatin } \\
\text {-3-(1-(4-methoxyphenylsulfonyl) }\end{array}$ & $\begin{array}{l}\text { rease, } \\
\text { NAB-sodium d butyrate, } \\
\text { stat, } \\
\text {,2,3,4-tetrahydroquinolin-6-yl) acr }\end{array}$ & $\begin{array}{l}\text { TSA-trichostatin A, } \\
\text { LBH589-panobinostat, } \\
\text { lostat, } \\
\text { ylamide. }\end{array}$ \\
\hline
\end{tabular}

Author Contributions: Conceptualization, A.W., J.K., E.O., J.C., M.H., A.P., P.M., K.O., A.R.-M., A.S.; resources, A.W., J.K., E.O., J.C., M.H., A.P., P.M., K.O.; writing—draft preparation, A.W., J.K., E.O., J.C., M.H., A.P., P.M., K.O.; editing, A.W., A.R.-M.; supervision, A.R.-M., A.S.; funding acquisition, A.S., E.O., A.W., A.R.-M.

Funding: The study was supported by Medical University of Lublin DS440/2018-2019 grant, The Polish Ministry of Science and Higher Education MNmb 402/2018-2019, MNmb 510/2016-2017 grants and Polish National Science Centre (NCN): DEC-2015/17/B/NZ1/01777 and DEC-2017/25/B/NZ4/02364.

Acknowledgments: The authors thank Agnieszka Styczynska for the editorial assistance and proofreading.

Conflicts of Interest: The authors declare no conflict of interest.

\section{References}

1. Davis, F.M.; Stewart, T.A.; Thompson, E.W.; Monteith, G.R. Targeting EMT in cancer: Opportunities for pharmacological intervention. Trends Pharmacol. Sci. 2014, 35, 479-488. [CrossRef] [PubMed]

2. Kalluri, R.; Weinberg, R.A. The basics of epithelial-mesenchymal transition. J. Clin. Investig. 2009, 119, 1420-1428. [CrossRef] [PubMed]

3. Fardi, M.; Solali, S.; Farshdousti Hagh, M. Epigenetic mechanisms as a new approach in cancer treatment: An updated review. Genes Dis. 2018, 5, 304-311. [CrossRef] [PubMed]

4. Ma, F.; Jiang, S.; Zhang, C. Recent advances in histone modification and histone modifying enzyme assays. Expert Rev. Mol. Diagn. 2018, 1-10. [CrossRef] [PubMed]

5. Grabarska, A.; Łuszczki, J.J.; Nowosadzka, E.; Gumbarewicz, E.; Jeleniewicz, W.; Dmoszyńska-Graniczka, M.; Kowalczuk, K.; Kupisz, K.; Polberg, K.; Stepulak, A. Histone Deacetylase Inhibitor SAHA as Potential Targeted Therapy Agent for Larynx Cancer Cells. J. Cancer 2017, 8, 19-28. [CrossRef] [PubMed]

6. Gumbarewicz, E.; Luszczki, J.J.; Wawruszak, A.; Dmoszynska-Graniczka, M.; Grabarska, A.J.; Jarząb, A.M.; Polberg, K.; Stepulak, A. Isobolographic analysis demonstrates additive effect of cisplatin and HDIs combined treatment augmenting their anti-cancer activity in lung cancer cell lines. Am. J. Cancer Res. 2016, 6, 2831-2845.

7. Wawruszak, A.; Luszczki, J.J.; Grabarska, A.; Gumbarewicz, E.; Dmoszynska-Graniczka, M.; Polberg, K.; Stepulak, A. Assessment of Interactions between Cisplatin and Two Histone Deacetylase Inhibitors in MCF7, T47D and MDA-MB-231 Human Breast Cancer Cell Lines-An Isobolographic Analysis. PLoS ONE 2015, 10, e0143013. [CrossRef]

8. Falkenberg, K.J.; Johnstone, R.W. Histone deacetylases and their inhibitors in cancer, neurological diseases and immune disorders. Nat. Rev. Drug Discov. 2014, 13, 673-691. [CrossRef] 
9. Hölscher, A.S.; Schulz, W.A.; Pinkerneil, M.; Niegisch, G.; Hoffmann, M.J. Combined inhibition of BET proteins and class I HDACs synergistically induces apoptosis in urothelial carcinoma cell lines. Clin. Epigenetics 2018, 10, 1. [CrossRef]

10. Yao, D.; Dai, C.; Peng, S. Mechanism of the mesenchymal-epithelial transition and its relationship with metastatic tumor formation. Mol. Cancer Res. 2011, 9, 1608-1620. [CrossRef]

11. Lan, X.; Lu, G.; Yuan, C.; Mao, S.; Jiang, W.; Chen, Y.; Jin, X.; Xia, Q. Valproic acid (VPA) inhibits the epithelial-mesenchymal transition in prostate carcinoma via the dual suppression of SMAD4. J. Cancer Res. Clin. Oncol. 2016, 142, 177-185. [CrossRef] [PubMed]

12. Nalls, D.; Tang, S.-N.; Rodova, M.; Srivastava, R.K.; Shankar, S. Targeting epigenetic regulation of miR-34a for treatment of pancreatic cancer by inhibition of pancreatic cancer stem cells. PLOS ONE 2011, 6, e24099. [CrossRef] [PubMed]

13. Wang, X.; Xu, J.; Wang, H.; Wu, L.; Yuan, W.; Du, J.; Cai, S. Trichostatin A, a histone deacetylase inhibitor, reverses epithelial-mesenchymal transition in colorectal cancer SW480 and prostate cancer PC3 cells. Biochem. Biophys. Res. Commun. 2015, 456, 320-326. [CrossRef] [PubMed]

14. Shah, P.; Gau, Y.; Sabnis, G. Histone deacetylase inhibitor entinostat reverses epithelial to mesenchymal transition of breast cancer cells by reversing the repression of E-cadherin. Breast Cancer Res. Treat. 2014, 143, 99-111. [CrossRef] [PubMed]

15. Ji, M.; Lee, E.J.; Kim, K.B.; Kim, Y.; Sung, R.; Lee, S.-J.; Kim, D.S.; Park, S.M. HDAC inhibitors induce epithelial-mesenchymal transition in colon carcinoma cells. Oncol. Rep. 2015, 33, 2299-2308. [CrossRef] [PubMed]

16. Suraweera, A.; O’Byrne, K.J.; Richard, D.J. Combination Therapy with Histone Deacetylase Inhibitors (HDACi) for the Treatment of Cancer: Achieving the Full Therapeutic Potential of HDACi. Front. Oncol. 2018, 8, 92. [CrossRef] [PubMed]

17. Ronnekleiv-Kelly, S.M.; Sharma, A.; Ahuja, N. Epigenetic therapy and chemosensitization in solid malignancy. Cancer Treat. Rev. 2017, 55, 200-208. [CrossRef]

18. Manal, M.; Chandrasekar, M.J.N.; Gomathi Priya, J.; Nanjan, M.J. Inhibitors of histone deacetylase as antitumor agents: A critical review. Bioorg. Chem. 2016, 67, 18-42. [CrossRef]

19. Sun, X.-J.; Man, N.; Tan, Y.; Nimer, S.D.; Wang, L. The Role of Histone Acetyltransferases in Normal and Malignant Hematopoiesis. Front. Oncol. 2015, 5, 108. [CrossRef]

20. Roche, J.; Bertrand, P. Inside HDACs with more selective HDAC inhibitors. Eur. J. Med. Chem. 2016, 121, 451-483. [CrossRef]

21. Yang, X.-J.; Seto, E. HATs and HDACs: From structure, function and regulation to novel strategies for therapy and prevention. Oncogene 2007, 26, 5310-5318. [CrossRef] [PubMed]

22. Chrun, E.S.; Modolo, F.; Daniel, F.I. Histone modifications: A review about the presence of this epigenetic phenomenon in carcinogenesis. Pathol. Res. Pract. 2017, 213, 1329-1339. [CrossRef] [PubMed]

23. Barneda-Zahonero, B.; Parra, M. Histone deacetylases and cancer. Mol. Oncol. 2012, 6, 579-589. [CrossRef] [PubMed]

24. He, Y.; Cai, C.; Tang, D.; Sun, S.; Li, H. Effect of histone deacetylase inhibitors trichostatin A and valproic acid on hair cell regeneration in zebrafish lateral line neuromasts. Front. Cell. Neurosci. 2014, 8, 382. [CrossRef] [PubMed]

25. Vickers, C.J.; Olsen, C.A.; Leman, L.J.; Ghadiri, M.R. Discovery of HDAC Inhibitors That Lack an Active Site $\mathrm{Zn}(2+)$-Binding Functional Group. ACS Med. Chem. Lett. 2012, 3, 505-508. [CrossRef] [PubMed]

26. Dang, W. The controversial world of sirtuins. Drug Discov. Today Technol. 2014, 12, e9-e17. [CrossRef] [PubMed]

27. Haberland, M.; Montgomery, R.L.; Olson, E.N. The many roles of histone deacetylases in development and physiology: Implications for disease and therapy. Nat. Rev. Genet. 2009, 10, 32-42. [CrossRef]

28. Lahm, A.; Paolini, C.; Pallaoro, M.; Nardi, M.C.; Jones, P.; Neddermann, P.; Sambucini, S.; Bottomley, M.J.; Lo Surdo, P.; Carfí, A.; et al. Unraveling the hidden catalytic activity of vertebrate class IIa histone deacetylases. Proc. Natl. Acad. Sci. USA 2007, 104, 17335-17340. [CrossRef]

29. Kaletsch, A.; Pinkerneil, M.; Hoffmann, M.J.; Jaguva Vasudevan, A.A.; Wang, C.; Hansen, F.K.; Wiek, C.; Hanenberg, H.; Gertzen, C.; Gohlke, H.; et al. Effects of novel HDAC inhibitors on urothelial carcinoma cells. Clin. Epigenetics 2018, 10, 100. [CrossRef] 
30. Fischle, W.; Dequiedt, F.; Hendzel, M.J.; Guenther, M.G.; Lazar, M.A.; Voelter, W.; Verdin, E. Enzymatic activity associated with class II HDACs is dependent on a multiprotein complex containing HDAC3 and SMRT/N-CoR. Mol. Cell 2002, 9, 45-57. [CrossRef]

31. Martin, M.; Kettmann, R.; Dequiedt, F. Class IIa histone deacetylases: Regulating the regulators. Oncogene 2007, 26, 5450-5467. [CrossRef] [PubMed]

32. Seto, E.; Yoshida, M. Erasers of histone acetylation: The histone deacetylase enzymes. Cold Spring Harb. Perspect. Biol. 2014, 6, a018713. [CrossRef] [PubMed]

33. Singh, A.; Bishayee, A.; Pandey, A. Targeting Histone Deacetylases with Natural and Synthetic Agents: An Emerging Anticancer Strategy. Nutrients 2018, 10, 731. [CrossRef] [PubMed]

34. Xu, J.; Wang, H.; Huang, G. Histone acetylation and congenital heart diseases. Chinese J. Pediatr. 2013, 51, 552-554.

35. Angiolilli, C.; Baeten, D.L.; Radstake, T.R.; Reedquist, K.A. The acetyl code in rheumatoid arthritis and other rheumatic diseases. Epigenomics 2017, 9, 447-461. [CrossRef] [PubMed]

36. Bonnaud, E.M.; Suberbielle, E.; Malnou, C.E. Histone acetylation in neuronal (dys)function. Biomol. Concepts 2016, 7, 103-116. [CrossRef] [PubMed]

37. Bayat, S.; Shekari Khaniani, M.; Choupani, J.; Alivand, M.R.; Mansoori Derakhshan, S. HDACis (class I), cancer stem cell, and phytochemicals: Cancer therapy and prevention implications. Biomed. Pharmacother. 2018, 97, 1445-1453. [CrossRef] [PubMed]

38. Giaginis, C.; Damaskos, C.; Koutsounas, I.; Zizi-Serbetzoglou, A.; Tsoukalas, N.; Patsouris, E.; Kouraklis, G.; Theocharis, S. Histone deacetylase (HDAC)-1, $-2,-4$ and -6 expression in human pancreatic adenocarcinoma: Associations with clinicopathological parameters, tumor proliferative capacity and patients' survival. BMC Gastroenterol. 2015, 15, 148. [CrossRef] [PubMed]

39. Shan, W.; Jiang, Y.; Yu, H.; Huang, Q.; Liu, L.; Guo, X.; Li, L.; Mi, Q.; Zhang, K.; Yang, Z. HDAC2 overexpression correlates with aggressive clinicopathological features and DNA-damage response pathway of breast cancer. Am. J. Cancer Res. 2017, 7, 1213-1226.

40. Ramakrishnan, S.; Ku, S.; Ciamporcero, E.; Miles, K.M.; Attwood, K.; Chintala, S.; Shen, L.; Ellis, L.; Sotomayor, P.; Swetzig, W.; et al. HDAC 1 and 6 modulate cell invasion and migration in clear cell renal cell carcinoma. BMC Cancer 2016, 16, 617. [CrossRef]

41. Damaskos, C.; Valsami, S.; Kontos, M.; Spartalis, E.; Kalampokas, T.; Kalampokas, E.; Athanasiou, A.; Moris, D.; Daskalopoulou, A.; Davakis, S.; et al. Histone Deacetylase Inhibitors: An Attractive Therapeutic Strategy Against Breast Cancer. Anticancer Res. 2017, 37, 35-46. [CrossRef] [PubMed]

42. Zhang, H.; Shang, Y.-P.; Chen, H.; Li, J. Histone deacetylases function as novel potential therapeutic targets for cancer. Hepatol. Res. 2017, 47, 149-159. [CrossRef] [PubMed]

43. Expression of HDAC1 in Cancer-Summary-The Human Protein Atlas. Available online: https://www. proteinatlas.org/ENSG00000116478-HDAC1/pathology (accessed on 10 January 2019).

44. Expression of HDAC2 in Cancer-Summary-The Human Protein Atlas. Available online: https://www. proteinatlas.org/ENSG00000196591-HDAC2/pathology (accessed on 10 January 2019).

45. Expression of HDAC3 in Cancer-Summary-The Human Protein Atlas. Available online: https://www. proteinatlas.org/ENSG00000171720-HDAC3/pathology (accessed on 10 January 2019).

46. Expression of HDAC8 in Cancer-Summary-The Human Protein Atlas. Available online: https://www. proteinatlas.org/ENSG00000147099-HDAC8/pathology (accessed on 10 January 2019).

47. Expression of HDAC4 in Cancer-Summary-The Human Protein Atlas. Available online: https://www. proteinatlas.org/ENSG00000068024-HDAC4/pathology (accessed on 10 January 2019).

48. Expression of HDAC5 in Cancer-Summary-The Human Protein Atlas. Available online: https://www. proteinatlas.org/ENSG00000108840-HDAC5/pathology (accessed on 10 January 2019).

49. Expression of HDAC9 in Cancer-Summary-The Human Protein Atlas. Available online: https://www. proteinatlas.org/ENSG00000048052-HDAC9/pathology (accessed on 10 January 2019).

50. Lei, Y.; Liu, L.; Zhang, S.; Guo, S.; Li, X.; Wang, J.; Su, B.; Fang, Y.; Chen, X.; Ke, H.; et al. Hdac7 promotes lung tumorigenesis by inhibiting Stat3 activation. Mol. Cancer 2017, 16, 170. [CrossRef] [PubMed]

51. Expression of HDAC10 in Cancer-Summary-The Human Protein Atlas. Available online: https://www. proteinatlas.org/ENSG00000100429-HDAC10/pathology (accessed on 10 January 2019).

52. Expression of HDAC6 in Cancer-Summary-The Human Protein Atlas. Available online: https://www. proteinatlas.org/ENSG00000094631-HDAC6/pathology (accessed on 10 January 2019). 
53. Expression of SIRT3 in Cancer-Summary-The Human Protein Atlas. Available online: https://www. proteinatlas.org/ENSG00000142082-SIRT3/pathology (accessed on 10 January 2019).

54. Expression of SIRT5 in Cancer-Summary-The Human Protein Atlas. Available online: https://www. proteinatlas.org/ENSG00000124523-SIRT5/pathology (accessed on 10 January 2019).

55. Expression of SIRT6 in Cancer-Summary-The Human Protein Atlas. Available online: https://www. proteinatlas.org/ENSG00000077463-SIRT6/pathology (accessed on 10 January 2019).

56. Expression of SIRT7 in Cancer-Summary-The Human Protein Atlas. Available online: https://www. proteinatlas.org/ENSG00000187531-SIRT7/pathology (accessed on 10 January 2019).

57. Expression of SIRT2 in Cancer-Summary-The Human Protein Atlas. Available online: https://www. proteinatlas.org/ENSG00000068903-SIRT2/pathology (accessed on 10 January 2019).

58. Deubzer, H.E.; Schier, M.C.; Oehme, I.; Lodrini, M.; Haendler, B.; Sommer, A.; Witt, O. HDAC11 is a novel drug target in carcinomas. Int. J. Cancer 2013, 132, 2200-2208. [CrossRef] [PubMed]

59. Expression of SIRT1 in Cancer-Summary-The Human Protein Atlas. Available online: https://www. proteinatlas.org/ENSG00000096717-SIRT1/pathology (accessed on 10 January 2019).

60. Expression of SIRT4 in Cancer-Summary-The Human Protein Atlas. Available online: https://www. proteinatlas.org/ENSG00000089163-SIRT4/pathology (accessed on 10 January 2019).

61. Niegisch, G.; Knievel, J.; Koch, A.; Hader, C.; Fischer, U.; Albers, P.; Schulz, W.A. Changes in histone deacetylase (HDAC) expression patterns and activity of HDAC inhibitors in urothelial cancers. Urol. Oncol. Semin. Orig. Investig. 2013, 31, 1770-1779. [CrossRef] [PubMed]

62. Pinkerneil, M.; Hoffmann, M.J.; Deenen, R.; Kohrer, K.; Arent, T.; Schulz, W.A.; Niegisch, G. Inhibition of Class I Histone Deacetylases 1 and 2 Promotes Urothelial Carcinoma Cell Death by Various Mechanisms. Mol. Cancer Ther. 2016, 15, 299-312. [CrossRef] [PubMed]

63. Lehmann, M.; Hoffmann, M.J.; Koch, A.; Ulrich, S.M.; Schulz, W.A.; Niegisch, G. Histone deacetylase 8 is deregulated in urothelial cancer but not a target for efficient treatment. J. Exp. Clin. Cancer Res. 2014, 33, 59. [CrossRef] [PubMed]

64. Chervona, Y.; Costa, M. Histone modifications and cancer: Biomarkers of prognosis? Am. J. Cancer Res. 2012, 2, 589-597.

65. Gobinet, J.; Carascossa, S.; Cavaillès, V.; Vignon, F.; Nicolas, J.-C.; Jalaguier, S. SHP represses transcriptional activity via recruitment of histone deacetylases. Biochemistry 2005, 44, 6312-6320. [CrossRef] [PubMed]

66. Narita, T.; Weinert, B.T.; Choudhary, C. Functions and mechanisms of non-histone protein acetylation. Nat. Rev. Mol. Cell Biol. 2018. [CrossRef]

67. Glozak, M.A.; Sengupta, N.; Zhang, X.; Seto, E. Acetylation and deacetylation of non-histone proteins. Gene 2005, 363, 15-23. [CrossRef] [PubMed]

68. Lee, J.S.; Galvin, K.M.; See, R.H.; Eckner, R.; Livingston, D.; Moran, E.; Shi, Y. Relief of YY1 transcriptional repression by adenovirus E1A is mediated by E1A-associated protein p300. Genes Dev. 1995, 9, 1188-1198. [CrossRef] [PubMed]

69. Lührs, H.; Hock, R.; Schauber, J.; Weihrauch, M.; Harrer, M.; Melcher, R.; Scheppach, W.; Bustin, M.; Menzel, T. Modulation of HMG-N2 binding to chromatin by butyrate-induced acetylation in human colon adenocarcinoma cells. Int. J. Cancer 2002, 97, 567-573. [CrossRef] [PubMed]

70. Edberg, D.D.; Bruce, J.E.; Siems, W.F.; Reeves, R. In Vivo Posttranslational Modifications of the High Mobility Group A1a Proteins in Breast Cancer Cells of Differing Metastatic Potential. Biochemistry 2004, 43, 11500-11515. [CrossRef] [PubMed]

71. Gaughan, L.; Logan, I.R.; Cook, S.; Neal, D.E.; Robson, C.N. Tip60 and Histone Deacetylase 1 Regulate Androgen Receptor Activity through Changes to the Acetylation Status of the Receptor. J. Biol. Chem. 2002, 277, 25904-25913. [CrossRef] [PubMed]

72. Boyes, J.; Byfield, P.; Nakatani, Y.; Ogryzko, V. Regulation of activity of the transcription factor GATA-1 by acetylation. Nature 1998, 396, 594-598. [CrossRef] [PubMed]

73. Zhang, W.; Bieker, J.J. Acetylation and modulation of erythroid Krüppel-like factor (EKLF) activity by interaction with histone acetyltransferases. Proc. Natl. Acad. Sci. USA 1998, 95, 9855-9860. [CrossRef] [PubMed]

74. Chen, L.; Mu, Y.; Greene, W.C. Acetylation of RelA at discrete sites regulates distinct nuclear functions of NF-kappaB. EMBO J. 2002, 21, 6539-6548. [CrossRef] 
75. Bali, P.; Pranpat, M.; Bradner, J.; Balasis, M.; Fiskus, W.; Guo, F.; Rocha, K.; Kumaraswamy, S.; Boyapalle, S.; Atadja, P.; et al. Inhibition of histone deacetylase 6 acetylates and disrupts the chaperone function of heat shock protein 90: A novel basis for antileukemia activity of histone deacetylase inhibitors. J. Biol. Chem. 2005, 280, 26729-26734. [CrossRef]

76. Jeong, J.W.; Bae, M.K.; Ahn, M.Y.; Kim, S.H.; Sohn, T.K.; Bae, M.H.; Yoo, M.A.; Song, E.J.; Lee, K.J.; Kim, K.W. Regulation and destabilization of HIF-1alpha by ARD1-mediated acetylation. Cell 2002, 111, 709-720. [CrossRef]

77. Simonsson, M.; Heldin, C.-H.; Ericsson, J.; Grönroos, E. The balance between acetylation and deacetylation controls Smad7 stability. J. Biol. Chem. 2005, 280, 21797-21803. [CrossRef] [PubMed]

78. Jin, K.; Zhou, W.; Han, X.; Wang, Z.; Li, B.; Jeffries, S.; Tao, W.; Robbins, D.J.; Capobianco, A.J. Acetylation of Mastermind-like 1 by p300 Drives the Recruitment of NACK to Initiate Notch-Dependent Transcription. Cancer Res. 2017, 77, 4228-4237. [CrossRef] [PubMed]

79. Zhao, D.; Mo, Y.; Li, M.-T.; Zou, S.-W.; Cheng, Z.-L.; Sun, Y.-P.; Xiong, Y.; Guan, K.-L.; Lei, Q.-Y. $\mathrm{NOTCH}$-induced aldehyde dehydrogenase $1 \mathrm{~A} 1$ deacetylation promotes breast cancer stem cells. J. Clin. Investig. 2014, 124, 5453-5465. [CrossRef] [PubMed]

80. Pinkerneil, M.; Hoffmann, M.J.; Kohlhof, H.; Schulz, W.A.; Niegisch, G. Evaluation of the Therapeutic Potential of the Novel Isotype Specific HDAC Inhibitor 4SC-202 in Urothelial Carcinoma Cell Lines. Target. Oncol. 2016, 11, 783-798. [CrossRef] [PubMed]

81. Qiu, X.; Xiao, X.; Li, N.; Li, Y. Histone deacetylases inhibitors (HDACis) as novel therapeutic application in various clinical diseases. Prog. Neuro-Psychopharmacol. Biol. Psychiatry 2017, 72, 60-72. [CrossRef] [PubMed]

82. Tasoulas, J.; Giaginis, C.; Patsouris, E.; Manolis, E.; Theocharis, S. Histone deacetylase inhibitors in oral squamous cell carcinoma treatment. Expert Opin. Investig. Drugs 2015, 24, 69-78. [CrossRef] [PubMed]

83. Kumar, S.; Tandon, N.; Ramakrishnan, V. Clinical use and applications of histone deacetylase inhibitors in multiple myeloma. Clin. Pharmacol. Adv. Appl. 2016, 8, 35. [CrossRef]

84. Kusaczuk, M.; Krętowski, R.; Bartoszewicz, M.; Cechowska-Pasko, M. Phenylbutyrate-a pan-HDAC inhibitor-suppresses proliferation of glioblastoma LN-229 cell line. Tumour Biol. 2016, 37, 931-942. [CrossRef] [PubMed]

85. Park, M.J.; Sohrabji, F. The histone deacetylase inhibitor, sodium butyrate, exhibits neuroprotective effects for ischemic stroke in middle-aged female rats. J. Neuroinflamm. 2016, 13, 300. [CrossRef]

86. Leng, Y.; Wang, J.; Wang, Z.; Liao, H.-M.; Wei, M.; Leeds, P.; Chuang, D.-M. Valproic Acid and Other HDAC Inhibitors Upregulate FGF21 Gene Expression and Promote Process Elongation in Glia by Inhibiting HDAC2 and 3. Int. J. Neuropsychopharmacol. 2016, 19. [CrossRef]

87. Zhou, W.; Feng, X.; Han Han, H.; Guo, S.; Wang, G. Synergistic effects of combined treatment with histone deacetylase inhibitor suberoylanilide hydroxamic acid and TRAIL on human breast cancer cells. Sci. Rep. 2016, 6, 28004. [CrossRef] [PubMed]

88. Foss, F.; Advani, R.; Duvic, M.; Hymes, K.B.; Intragumtornchai, T.; Lekhakula, A.; Shpilberg, O.; Lerner, A.; Belt, R.J.; Jacobsen, E.D.; et al. A Phase II trial of Belinostat (PXD101) in patients with relapsed or refractory peripheral or cutaneous T-cell lymphoma. Br. J. Haematol. 2015, 168, 811-819. [CrossRef] [PubMed]

89. Wightman, F.; Lu, H.K.; Solomon, A.E.; Saleh, S.; Harman, A.N.; Cunningham, A.L.; Gray, L.; Churchill, M.; Cameron, P.U.; Dear, A.E.; et al. Entinostat is a histone deacetylase inhibitor selective for class 1 histone deacetylases and activates HIV production from latently infected primary T cells. AIDS 2013, 27, 2853-2862. [CrossRef] [PubMed]

90. Zhang, Q.; Sun, M.; Zhou, S.; Guo, B. Class I HDAC inhibitor mocetinostat induces apoptosis by activation of miR-31 expression and suppression of E2F6. Cell Death Discov. 2016, 2, 16036. [CrossRef] [PubMed]

91. Petrich, A.; Nabhan, C. Use of class I histone deacetylase inhibitor romidepsin in combination regimens. Leuk. Lymphoma 2016, 57, 1755-1765. [CrossRef] [PubMed]

92. Igotti Abramova, M.V.; Pojidaeva, A.K.; Filippova, E.A.; Gnedina, O.O.; Svetlikova, S.B.; Pospelov, V.A. HDAC inhibitors induce apoptosis but not cellular senescence in Gadd45 $\alpha$-deficient E1A+Ras cells. Int. J. Biochem. Cell Biol. 2014, 51, 102-110. [CrossRef] [PubMed]

93. Bao, L.; Diao, H.; Dong, N.; Su, X.; Wang, B.; Mo, Q.; Yu, H.; Wang, X.; Chen, C. Histone deacetylase inhibitor induces cell apoptosis and cycle arrest in lung cancer cells via mitochondrial injury and p53 up-acetylation. Cell Biol. Toxicol. 2016, 32, 469-482. [CrossRef] 
94. Stepulak, A.; Stryjecka-Zimmer, M.; Kupisz, K.; Polberg, K. Histone deacetylase inhibitors as a new generation of anti-cancer agents. Postepy Hig. Med. Dosw. 2005, 59, 68-74.

95. Osuka, S.; Takano, S.; Watanabe, S.; Ishikawa, E.; Yamamoto, T.; Matsumura, A. Valproic acid inhibits angiogenesis in vitro and glioma angiogenesis in vivo in the brain. Neurol. Med. Chir. 2012, 52, 186-193. [CrossRef]

96. VanderMolen, K.M.; McCulloch, W.; Pearce, C.J.; Oberlies, N.H. Romidepsin (Istodax, NSC 630176, FR901228, FK228, depsipeptide): A natural product recently approved for cutaneous T-cell lymphoma. J. Antibiot. 2011, 64, 525-531. [CrossRef]

97. Kim, E.; Bisson, W.H.; Löhr, C.V.; Williams, D.E.; Ho, E.; Dashwood, R.H.; Rajendran, P. Histone and Non-Histone Targets of Dietary Deacetylase Inhibitors. Curr. Top. Med. Chem. 2016, 16, 714-731. [CrossRef] [PubMed]

98. Gurzu, S.; Turdean, S.; Kovecsi, A.; Contac, A.O.; Jung, I. Epithelial-mesenchymal, mesenchymal-epithelial, and endothelial-mesenchymal transitions in malignant tumors: An update. World J. Clin. Cases 2015, 3, 393. [CrossRef] [PubMed]

99. Barriere, G.; Fici, P.; Gallerani, G.; Fabbri, F.; Rigaud, M. Epithelial Mesenchymal Transition: A double-edged sword. Clin. Transl. Med. 2015, 4, 14. [CrossRef] [PubMed]

100. Huang, R.Y.-J.; Guilford, P.; Thiery, J.P. Early events in cell adhesion and polarity during epithelial-mesenchymal transition. J. Cell Sci. 2012, 125, 4417-4422. [CrossRef] [PubMed]

101. Nieto, M.A.; Huang, R.Y.-J.; Jackson, R.A.; Thiery, J.P. EMT: 2016. Cell 2016, 166, 21-45. [CrossRef] [PubMed]

102. Lamouille, S.; Xu, J.; Derynck, R. Molecular mechanisms of epithelial-mesenchymal transition. Nat. Rev. Mol. Cell Biol. 2014, 15, 178-196. [CrossRef] [PubMed]

103. Francart, M.-E.; Lambert, J.; Vanwynsberghe, A.M.; Thompson, E.W.; Bourcy, M.; Polette, M.; Gilles, C. Epithelial-mesenchymal plasticity and circulating tumor cells: Travel companions to metastases. Dev. Dyn. 2018, 247, 432-450. [CrossRef] [PubMed]

104. Liu, C.-Y.; Lin, H.-H.; Tang, M.-J.; Wang, Y.-K. Vimentin contributes to epithelial-mesenchymal transition cancer cell mechanics by mediating cytoskeletal organization and focal adhesion maturation. Oncotarget 2015, 6, 15966-15983. [CrossRef]

105. Wong, S.H.M.; Fang, C.M.; Chuah, L.-H.; Leong, C.O.; Ngai, S.C. E-cadherin: Its dysregulation in carcinogenesis and clinical implications. Crit. Rev. Oncol. Hematol. 2018, 121, 11-22. [CrossRef]

106. Skrypek, N.; Goossens, S.; De Smedt, E.; Vandamme, N.; Berx, G. Epithelial-to-Mesenchymal Transition: Epigenetic Reprogramming Driving Cellular Plasticity. Trends Genet. 2017, 33, 943-959. [CrossRef]

107. Wang, Y.; Shi, J.; Chai, K.; Ying, X.; Zhou, B.P. The Role of Snail in EMT and Tumorigenesis. Curr. Cancer Drug Targets 2013, 13, 963-972. [CrossRef] [PubMed]

108. Gheldof, A.; Hulpiau, P.; van Roy, F.; De Craene, B.; Berx, G. Evolutionary functional analysis and molecular regulation of the ZEB transcription factors. Cell. Mol. Life Sci. 2012, 69, 2527-2541. [CrossRef] [PubMed]

109. Garg, M. Epithelial, mesenchymal and hybrid epithelial/mesenchymal phenotypes and their clinical relevance in cancer metastasis. Expert Rev. Mol. Med. 2017, 19, e3. [CrossRef] [PubMed]

110. Lo, H.C.; Zhang, X.H.-F. EMT in Metastasis: Finding the Right Balance. Dev. Cell 2018, 45, 663-665. [CrossRef] [PubMed]

111. Pastushenko, I.; Brisebarre, A.; Sifrim, A.; Fioramonti, M.; Revenco, T.; Boumahdi, S.; Van Keymeulen, A.; Brown, D.; Moers, V.; Lemaire, S.; et al. Identification of the tumour transition states occurring during EMT. Nature 2018, 556, 463-468. [CrossRef] [PubMed]

112. Jolly, M.K.; Boareto, M.; Debeb, B.G.; Aceto, N.; Farach-Carson, M.C.; Woodward, W.A.; Levine, H. Inflammatory breast cancer: A model for investigating cluster-based dissemination. NPJ Breast Cancer 2017, 3, 21. [CrossRef] [PubMed]

113. Tang, H.M.; Kuay, K.T.; Koh, P.F.; Asad, M.; Tan, T.Z.; Chung, V.Y.; Lee, S.C.; Thiery, J.P.; Huang, R.-J. An epithelial marker promoter induction screen identifies histone deacetylase inhibitors to restore epithelial differentiation and abolishes anchorage independence growth in cancers. Cell Death Discov. 2016, 2, 16041. [CrossRef] [PubMed]

114. Nagaraja, S.S.; Krishnamoorthy, V.; Raviraj, R.; Paramasivam, A.; Nagarajan, D. Effect of Trichostatin A on radiation induced epithelial-mesenchymal transition in A549 cells. Biochem. Biophys. Res. Commun. 2017, 493, 1534-1541. [CrossRef] [PubMed] 
115. Park, I.-H.; Kang, J.-H.; Shin, J.-M.; Lee, H.-M. Trichostatin A Inhibits Epithelial Mesenchymal Transition Induced by TGF- $\beta 1$ in Airway Epithelium. PLoS ONE 2016, 11, e0162058. [CrossRef]

116. Mateen, S.; Raina, K.; Agarwal, C.; Chan, D.; Agarwal, R. Silibinin synergizes with histone deacetylase and DNA methyltransferase inhibitors in upregulating E-cadherin expression together with inhibition of migration and invasion of human non-small cell lung cancer cells. J. Pharmacol. Exp. Ther. 2013, 345, $206-214$. [CrossRef]

117. Noguchi, S.; Eitoku, M.; Moriya, S.; Kondo, S.; Kiyosawa, H.; Watanabe, T.; Suganuma, N. Regulation of Gene Expression by Sodium Valproate in Epithelial-to-Mesenchymal Transition. Lung 2015, 193, 691-700. [CrossRef] [PubMed]

118. Wang, J.; Xu, M.; Jiang, X.; Mei, X.; Liu, X. Histone deacetylase inhibitor SAHA-induced epithelial-mesenchymal transition by upregulating Slug in lung cancer cells. Anticancer Drugs 2018, 29, 80-88. [CrossRef] [PubMed]

119. Wu, Y.; Lyu, H.; Liu, H.; Shi, X.; Song, Y.; Liu, B. Downregulation of the long noncoding RNA GAS5-AS1 contributes to tumor metastasis in non-small cell lung cancer. Sci. Rep. 2016, 6, 31093. [CrossRef] [PubMed]

120. Yang, L.; Chang, Y.; Cao, P. CCR7 preservation via histone deacetylase inhibition promotes epithelial-mesenchymal transition of hepatocellular carcinoma cells. Exp. Cell Res. 2018, 371, 231-237. [CrossRef] [PubMed]

121. Xu, W.; Liu, H.; Liu, Z.-G.; Wang, H.-S.; Zhang, F.; Wang, H.; Zhang, J.; Chen, J.-J.; Huang, H.-J.; Tan, Y.; et al. Histone deacetylase inhibitors upregulate Snail via Smad2/3 phosphorylation and stabilization of Snail to promote metastasis of hepatoma cells. Cancer Lett. 2018, 420, 1-13. [CrossRef] [PubMed]

122. Song, X.; Wang, J.; Zheng, T.; Song, R.; Liang, Y.; Bhatta, N.; Yin, D.; Pan, S.; Liu, J.; Jiang, H.; et al. LBH589 Inhibits proliferation and metastasis of hepatocellular carcinoma via inhibition of gankyrin/STAT3/Akt pathway. Mol. Cancer 2013, 12, 114. [CrossRef] [PubMed]

123. Soukupova, J.; Bertran, E.; Peñuelas-Haro, I.; Urdiroz-Urricelqui, U.; Borgman, M.; Kohlhof, H.; Fabregat, I. Resminostat induces changes in epithelial plasticity of hepatocellular carcinoma cells and sensitizes them to sorafenib-induced apoptosis. Oncotarget 2017, 8, 110367-110379. [CrossRef] [PubMed]

124. Wang, J.; Lee, E.; Ji, M.; Park, S. HDAC inhibitors, trichostatin A and valproic acid, increase E-cadherin and vimentin expression but inhibit migration and invasion of cholangiocarcinoma cells. Oncol. Rep. 2018, 40, 346-354. [CrossRef]

125. Mishra, V.K.; Wegwitz, F.; Kosinsky, R.L.; Sen, M.; Baumgartner, R.; Wulff, T.; Siveke, J.T.; Schildhaus, H.-U.; Najafova, Z.; Kari, V.; et al. Histone deacetylase class-I inhibition promotes epithelial gene expression in pancreatic cancer cells in a BRD4- and MYC-dependent manner. Nucleic Acids Res. 2017, 45, 6334-6349. [CrossRef] [PubMed]

126. Polireddy, K.; Dong, R.; McDonald, P.R.; Wang, T.; Luke, B.; Chen, P.; Broward, M.; Roy, A.; Chen, Q. Targeting Epithelial-Mesenchymal Transition for Identification of Inhibitors for Pancreatic Cancer Cell Invasion and Tumor Spheres Formation. PLoS ONE 2016, 11, e0164811. [CrossRef] [PubMed]

127. Meidhof, S.; Brabletz, S.; Lehmann, W.; Preca, B.-T.; Mock, K.; Ruh, M.; Schüler, J.; Berthold, M.; Weber, A.; Burk, U.; et al. ZEB1-associated drug resistance in cancer cells is reversed by the class I HDAC inhibitor mocetinostat. EMBO Mol. Med. 2015, 7, 831-847. [CrossRef] [PubMed]

128. Lazarova, D.; Bordonaro, M. ZEB1 Mediates Drug Resistance and EMT in p300-Deficient CRC. J. Cancer 2017, 8, 1453-1459. [CrossRef] [PubMed]

129. Chen, C.-H.; Lee, C.-H.; Liou, J.-P.; Teng, C.-M.; Pan, S.-L. Molecular mechanisms underlying the antitumor activity of (E)-N-hydroxy-3-(1-(4-methoxyphenylsulfonyl)-1,2,3,4-tetrahydroquinolin-6-yl)acrylamide in human colorectal cancer cells in vitro and in vivo. Oncotarget 2015, 6, 35991-36002. [CrossRef] [PubMed]

130. Kiweler, N.; Brill, B.; Wirth, M.; Breuksch, I.; Laguna, T.; Dietrich, C.; Strand, S.; Schneider, G.; Groner, B.; Butter, F.; et al. The histone deacetylases HDAC1 and HDAC2 are required for the growth and survival of renal carcinoma cells. Arch. Toxicol. 2018, 92, 2227-2243. [CrossRef] [PubMed]

131. Choi, S.Y.; Kee, H.J.; Kurz, T.; Hansen, F.K.; Ryu, Y.; Kim, G.R.; Lin, M.Q.; Jin, L.; Piao, Z.H.; Jeong, M.H. Class I HDACs specifically regulate E-cadherin expression in human renal epithelial cells. J. Cell. Mol. Med. 2016, 20, 2289-2298. [CrossRef] [PubMed]

132. Skowron, M.A.; Sathe, A.; Romano, A.; Hoffmann, M.J.; Schulz, W.A.; van Koeveringe, G.A.; Albers, P.; Nawroth, R.; Niegisch, G. Applying the chicken embryo chorioallantoic membrane assay to study treatment approaches in urothelial carcinoma. Urol. Oncol. Semin. Orig. Investig. 2017, 35, 544.e11-544.e23. [CrossRef] 
133. Elshafae, S.M.; Kohart, N.A.; Altstadt, L.A.; Dirksen, W.P.; Rosol, T.J. The Effect of a Histone Deacetylase Inhibitor (AR-42) on Canine Prostate Cancer Growth and Metastasis. Prostate 2017, 77, 776-793. [CrossRef] [PubMed]

134. McLeod, A.B.; Stice, J.P.; Wardell, S.E.; Alley, H.M.; Chang, C.; McDonnell, D.P. Validation of histone deacetylase 3 as a therapeutic target in castration-resistant prostate cancer. Prostate 2018, 78, 266-277. [CrossRef]

135. Sakamoto, T.; Kobayashi, S.; Yamada, D.; Nagano, H.; Tomokuni, A.; Tomimaru, Y.; Noda, T.; Gotoh, K.; Asaoka, T.; Wada, H.; et al. A Histone Deacetylase Inhibitor Suppresses Epithelial-Mesenchymal Transition and Attenuates Chemoresistance in Biliary Tract Cancer. PLoS ONE 2016, 11, e0145985. [CrossRef]

136. Wu, S.; Luo, Z.; Yu, P.-J.; Xie, H.; He, Y.-W. Suberoylanilide hydroxamic acid (SAHA) promotes the epithelial mesenchymal transition of triple negative breast cancer cells via HDAC8/FOXA1 signals. Biol. Chem. 2016, 397. [CrossRef]

137. Debeb, B.G.; Lacerda, L.; Xu, W.; Larson, R.; Solley, T.; Atkinson, R.; Sulman, E.P.; Ueno, N.T.; Krishnamurthy, S.; Reuben, J.M.; et al. Histone deacetylase inhibitors stimulate dedifferentiation of human breast cancer cells through WNT/ $\beta$-catenin signaling. Stem Cells 2012, 30, 2366-2377. [CrossRef] [PubMed]

138. Rhodes, L.V.; Tate, C.R.; Segar, H.C.; Burks, H.E.; Phamduy, T.B.; Hoang, V.; Elliott, S.; Gilliam, D.; Pounder, F.N.; Anbalagan, M.; et al. Suppression of triple-negative breast cancer metastasis by pan-DAC inhibitor panobinostat via inhibition of ZEB family of EMT master regulators. Breast Cancer Res. Treat. 2014, 145, 593-604. [CrossRef] [PubMed]

139. Srivastava, R.K.; Kurzrock, R.; Shankar, S. MS-275 Sensitizes TRAIL-Resistant Breast Cancer Cells, Inhibits Angiogenesis and Metastasis, and Reverses Epithelial-Mesenchymal Transition In vivo. Mol. Cancer Ther. 2010, 9, 3254-3266. [CrossRef] [PubMed]

140. Meng, F.; Sun, G.; Zhong, M.; Yu, Y.; Brewer, M.A. Anticancer efficacy of cisplatin and trichostatin A or 5-aza-2'-deoxycytidine on ovarian cancer. Br. J. Cancer 2013, 108, 579-586. [CrossRef] [PubMed]

141. Bruzzese, F.; Leone, A.; Rocco, M.; Carbone, C.; Piro, G.; Caraglia, M.; Di Gennaro, E.; Budillon, A. HDAC inhibitor vorinostat enhances the antitumor effect of gefitinib in squamous cell carcinoma of head and neck by modulating ErbB receptor expression and reverting EMT. J. Cell. Physiol. 2011, 226, 2378-2390. [CrossRef] [PubMed]

142. Kanamoto, A.; Ninomiya, I.; Harada, S.; Tsukada, T.; Okamoto, K.; Nakanuma, S.; Sakai, S.; Makino, I.; Kinoshita, J.; Hayashi, H.; et al. Valproic acid inhibits irradiation-induced epithelial-mesenchymal transition and stem cell-like characteristics in esophageal squamous cell carcinoma. Int. J. Oncol. 2016, 49, 1859-1869. [CrossRef] [PubMed]

143. Choi, E.J.; Cho, B.J.; Lee, D.J.; Hwang, Y.H.; Chun, S.H.; Kim, H.H.; Kim, I.A. Enhanced cytotoxic effect of radiation and temozolomide in malignant glioma cells: Targeting PI3K-AKT-mTOR signaling, HSP90 and histone deacetylases. BMC Cancer 2014, 14, 17. [CrossRef] [PubMed]

144. Shankar, S.; Nall, D.; Tang, S.-N.; Meeker, D.; Passarini, J.; Sharma, J.; Srivastava, R.K. Resveratrol inhibits pancreatic cancer stem cell characteristics in human and KrasG12D transgenic mice by inhibiting pluripotency maintaining factors and epithelial-mesenchymal transition. PLoS ONE 2011, 6, e16530. [CrossRef]

145. Yoshikawa, M.; Hishikawa, K.; Marumo, T.; Fujita, T. Inhibition of Histone Deacetylase Activity Suppresses Epithelial-to-Mesenchymal Transition Induced by TGF-beta1 in Human Renal Epithelial Cells. J. Am. Soc. Nephrol. 2007, 18, 58-65. [CrossRef]

146. Ruscetti, M.; Dadashian, E.L.; Guo, W.; Quach, B.; Mulholland, D.J.; Park, J.W.; Tran, L.M.; Kobayashi, N.; Bianchi-Frias, D.; Xing, Y.; et al. HDAC inhibition impedes epithelial-mesenchymal plasticity and suppresses metastatic, castration-resistant prostate cancer. Oncogene 2016, 35, 3781-3795. [CrossRef]

147. Sarkar, S.; Goldgar, S.; Byler, S.; Rosenthal, S.; Heerboth, S. Demethylation and re-expression of epigenetically silenced tumor suppressor genes: Sensitization of cancer cells by combination therapy. Epigenomics 2013, 5, 87-94. [CrossRef] [PubMed]

148. Kazanets, A.; Shorstova, T.; Hilmi, K.; Marques, M.; Witcher, M. Epigenetic silencing of tumor suppressor genes: Paradigms, puzzles, and potential. Biochim. Biophys. Acta Rev. Cancer 2016, 1865, 275-288. [CrossRef] [PubMed] 
149. Lefter, L.P.; Dima, S.; Sunamura, M.; Furukawa, T.; Sato, Y.; Abe, M.; Chivu, M.; Popescu, I.; Horii, A. Transcriptional silencing of ETS-1 efficiently suppresses angiogenesis of pancreatic cancer. Cancer Gene Ther. 2009, 16, 137-148. [CrossRef] [PubMed]

150. Avgustinova, A.; Symeonidi, A.; Castellanos, A.; Urdiroz-Urricelqui, U.; Solé-Boldo, L.; Martín, M.; Pérez-Rodríguez, I.; Prats, N.; Lehner, B.; Supek, F.; et al. Loss of G9a preserves mutation patterns but increases chromatin accessibility, genomic instability and aggressiveness in skin tumours. Nat. Cell Biol. 2018, 20, 1400-1409. [CrossRef] [PubMed] 